\title{
Impact of Revascularization on the Distal to Proximal Pressure Ratio in Case of Multiple Coronary Stenoses
}

\author{
Amédéo Anselmi ${ }^{1}$, Hervé Corbineau ${ }^{1}$, Jean-Philippe Verhoye ${ }^{1}$, Agnès Drochon ${ }^{2}$ (i) \\ ${ }^{1}$ Department of Thoracic and Cardio-Vascular Surgery, Rennes Hospital Center, Rennes, France; ${ }^{2}$ UMR CNRS 5295, \\ Arts et Metiers Institute of Technology, University of Bordeaux, Bordeaux, France \\ Correspondence to: Agnès Drochon, agnes.drochon@u-bordeaux.fr \\ Keywords: Coronary Three-Vessel Disease, Hydrodynamic Impact of Stenoses, By-Pass Grafting, Fractional Flow \\ Reserve, Collateral Flow, Analog Electric Model, Flow and Pressure Simulations \\ Received: January 18, $2021 \quad$ Accepted: March 28, $2021 \quad$ Published: March 31, 2021
}

Copyright $\odot 2021$ by author(s) and Scientific Research Publishing Inc.

This work is licensed under the Creative Commons Attribution International License (CC BY 4.0).

http://creativecommons.org/licenses/by/4.0/

(c) (i) Open Access

\section{ABSTRACT}

Objective: In order to take a decision about the revascularization approach to be adopted, it is of fundamental importance to determine whether coronary artery stenoses induce ischemia or not. An index, named (Fractional Flow Reserve), based on pressure measurements has been proposed to this aim and is usually interpreted in terms of flows. The objective of this work is to compute simultaneously pressures and flow rates in the coronary network of patients with three-vessel disease, in order to study more precisely the relationship between these two quantities. Approach: 22 patients have been included in the study. Some pressure and flow rate measurements were collected during by-pass surgery. These clinical data allow determining parameters for a patient's specific model, based on the electric/hydraulic analogy. Collateral pathways are included in the model, as well as the severity of the disease and the impact of revascularization. Main Results: For patients with stenoses on LAD, LCx, LMCA and occlusion of the RCA, the flow rate delivered to the right territory is of course a function of the aortic pressure, the left stenoses severity, and the pressure distal to the thrombosis. But it mainly depends on the capillary and collateral resistances, and on the proportion between them. Abnormal microvascular hemodynamics, may be present in patients with non-hemodynamic significant lesions as assessed by the pressure ratio. Complete revascularization with the 3 grafts is demonstrated to be fully justified. The direction of collateral flows may be reversed, depending on the pressure gradient. In any case, they remain low and become negligible when the 3 grafts are operating. Significance: Surgical decision based only on pressure measurements may miss some real hemodynamic problems due to the considered stenosis. This risk is even greater in case of serial stenoses. 


\section{INTRODUCTION}

In order to take a decision about the revascularization approach to be adopted, it is of fundamental importance to determine whether coronary artery stenoses induce ischemia or not. The FFR index has been proposed for this aim in 1993 [1]. It is derived from the ratio of the mean pressure distal to the stenosis to the mean proximal pressure. It was initially validated for isolated lesions and requires maximal hyperemia conditions that are pharmacologically induced. Under such conditions (maximal vasodilation), the distal micro-vascular resistances are minimal, and FFR is said to represent the maximally achievable blood flow in the presence of a stenosis divided by the maximum flow expected in absence of the lesion. It is commonly admitted that FFR values higher than 0.8 indicate a sufficient blood irrigation of the downstream territory. However, FFR measurement needs to insert a pressure guide-wire in the stenosed artery, which itself creates hydrodynamic perturbations [2], and failure to achieve maximal hyperemia would result in an inaccuracy of the result. In some cases, the procedure is not possible at all: small or tortuous vessels, adverse reaction to the drug...

Moreover, the transposition of the FFR concept to the case of serial lesions is not straightforward. Due to the presence of a second stenosis in the artery, the condition of maximal vasodilation may not be achieved. The two lesions impact each other, especially if they are particularly severe, close together, non-concentric.

In order to overcome these limitations, some groups $[3,4]$ proposed to combine angiography techniques (coronary computed tomography angiography (cCTA)) and computational fluid dynamics (CFD) to get computed (or virtual) estimations of the FFR index, based on the medical images of each patient's coronary network. This requires detailed vessel segmentation procedure and mesh generation and the numerical simulations are time-consuming. Other difficulties may occur: complex anatomy, calcifications, motion artifacts, poor quality of the images... The 3-dimensional computations of flow and pressure in the diseased arteries rely on the resolution of Navier-Stokes equations, which are not exactly appropriate in the cases where turbulent flows exist. The other important point in the computed FFR approach is the boundary conditions applied at the end of the reconstructed vessels [5-7]. The microcirculatory bed resistances may be obtained from scaling laws of branches, relating organ size to its perfusion rate [3], or they are chosen as averaged values coming from previous studies [4]. These microvascular resistances determine the flow rate through the stenosis and consequently the distal pressure. Such computational predictions are much more difficult in case of multiple vessel disease, since the individual FFR of a stenosis gets affected by the presence of other lesions, and there is a need for incorporating patient-specific physiological parameters when modeling the downstream coronary resistances.

In the work presented here, the 0-dimensional approach is adopted (some introduction to the 0D models can be found in $[8,9]$ ). Contrary to the $3 \mathrm{D}$ models, lumped parameter models do not allow calculating the velocity or shear stress at any point of a vessel, but they have the benefit of requiring less time and computational resources than 3D models. For this reason, this approach may be more affordable in clinical routine. The clinical situation studied is severe multi-vessel coronary disease: patients have stenoses of the left main coronary artery (LMCA), left anterior descending artery (LAD) and left circumflex branch (LCx), and chronic occlusion of the right coronary artery (RCA). In some patients, the coronary disease may have induced the development of a collateral circulation. Bypass grafting has been performed to obtain myocardial reperfusion distal to these critical coronary stenoses or thromboses. In previously published papers $[10,11]$, we proposed a model based on hydraulic/electric analogy that describes this coronary artery system mathematically. The MatLab simulations allow studying the influence of the severity of native artery stenoses, of the degree of collateral supply developed by the patients and of the revascularization status (no grafts, left grafts only, complete revascularization). These calculations may be considered as patient's specific because the capillary and collateral resistances of each patient are deduced from its own clinical data. These quantitative values of capillary resistances based on physiological measurements may be used as boundary parameters for 3D computational models. Besides, the simulations pro- 
vide functional information about each stenosis: pressure data can be analyzed together with flows, in relation with the actual distal resistances.

In the first part of the paper, the procedure for clinical data collection and the principle of the electric model are briefly recalled. Then the detailed results are shown for each patient, and an analysis of the simulated pressure values is proposed in terms of distal to proximal pressure ratio for the stenoses.

\section{MATERIALS AND METHODS}

\subsection{Clinical Data}

The current study did not entail any additional therapeutic procedure other than conventional management (coronary bypass). Patients signed an informed consent to enter this observational study and for the management of personal data with research purposes. Data were managed anonymously.

The reductions in diameter and area of the stenosed arteries were estimated from standard angiographic techniques, before surgery. Angiograms were analyzed by quantitative coronary angiography (QCA) and visual inspection by the cardiologists.

Additional clinical informations (Rentrop Score, left ventricular ejection fraction, diabetes, previous stents, history of myocardial infarction) were also collected for each of the patients included in the study.

The off-pump coronary surgical procedure has been described previously in $[12,13]$. The RCA is first revascularized via a saphenous vein graft. Two series of measurements are performed: $P_{\text {ao }}$ (aortic pressure), $P_{\mathrm{v}}$ (central venous pressure), $P_{\mathrm{w}}$ (pressure distal to the RCA occlusion), with the right graft clamped $(0 \mathrm{G})$; and $P_{\text {ao }}, P_{\mathrm{v}}, Q_{\mathrm{RCAg}}$ (flow rate in the RCA graft) with the right graft opened (1G). The left coronary arteries are then revascularized via the internal thoracic arteries. Two additional series of measurements are performed: $P_{\mathrm{ao}}, P_{\mathrm{v}}, P_{\mathrm{w}}, Q_{\mathrm{LADg}}$ and $Q_{\mathrm{LCxg}}$ (flow rates in the LAD and LCx grafts) with the right graft clamped $(2 \mathrm{G})$; and $P_{\mathrm{ao}}, P_{\mathrm{v}}, Q_{\mathrm{LADg}}, Q_{\mathrm{LCxg}}$ and $Q_{\mathrm{RCAg}}$ with the right graft opened (3G). Flow rates are measured with an ultrasonic transit time flowmeter (Butterfly Flowmeter 2001; Medi-Stim, Oslo, Norway), after hemodynamic stabilization. All the quantities (flow rates and pressures) are registered as a function of time, but in this study, we focus on averaged values (over a cardiac cycle). This is consistent with the definition of the FFR index, that is based on mean pressure differences over time [14].

These clinical values of flow rates and pressures allow us to determine some parameters of the model, as explained in the next Section.

\subsection{Model Based on the Electrical Analogy}

The three-vessel disease coronary network of the patients included in the study is represented by the electrical analog shown in Figure 1. The hydraulic/electric analogy has yet been demonstrated by several authors $[8,9]$. Pressure and flow rate correspond to electrical voltage and current, respectively. Each segment of the coronary artery can be simulated by an elementary impedance with resistance $R$ (hydraulic resistance of the vessel), capacitance $C$ (compliance of the vessel) and inductance $L$ (inertia of the flowing blood). The notations are as follows: for LMCA: $R_{\mathrm{LMCA}}, C_{\mathrm{LMCA}}$ and $L_{\mathrm{LMCA}}$, for LAD: $R_{\mathrm{LAD}}, C_{\mathrm{LAD}}$ and $L_{\mathrm{LAD}}$, for $\mathrm{LCx}: R_{\mathrm{LCX}}, C_{\mathrm{LCX}}$ and $L_{\mathrm{LCX}}$, for RCA: $R_{\mathrm{RCA}}, C_{\mathrm{RCA}}$ and $L_{\mathrm{RCA}}$. Since the internal mammary arteries and the saphenous vein graft have different histological structure and mechanical properties, the grafts (IMAG, used for left coronary artery bypasses, and SVG, used for the RCA) were represented as suggested by Pietrabissa et al. [15]. To take into account tapering, the IMAG is artificially divided into two segments of equal length $(70 \mathrm{~mm})$ but of different diameters $(2.8 \mathrm{~mm}$ and $2 \mathrm{~mm}$, respectively); consequently, it is modeled by five elements: two resistances $R_{\mathrm{IMAG} 1}, R_{\mathrm{IMAG} 2}$; two coils $L_{\mathrm{IMAG} 1}, L_{\mathrm{IMAG} 2}$; and a capacitor $C_{\mathrm{IMAG}}$. SVG is modeled by two elements: a resistance $R_{\mathrm{SVG}}$ and a coil $L_{\mathrm{SVG}}$. The SVG model does not include an electric capacitance as experimental data confirm that when a vein is exposed to arterial pressure it loses its high compliance characteristics. The myocardial capillaries fed by the left and right coronary arteries are represented only by their resistances $R_{\mathrm{LADc}}, R_{\mathrm{LCXc}}$ and $R_{\mathrm{RCAc}}$. This approximation is convenient since the resistive effects are preponderant for small diameter vessels like capillaries. For the same reason, the collateral vessels are also represented only by their resistances $R_{\text {coli }}, i=1-5$. The blood flow rates across the LAD, LCx and RCA 


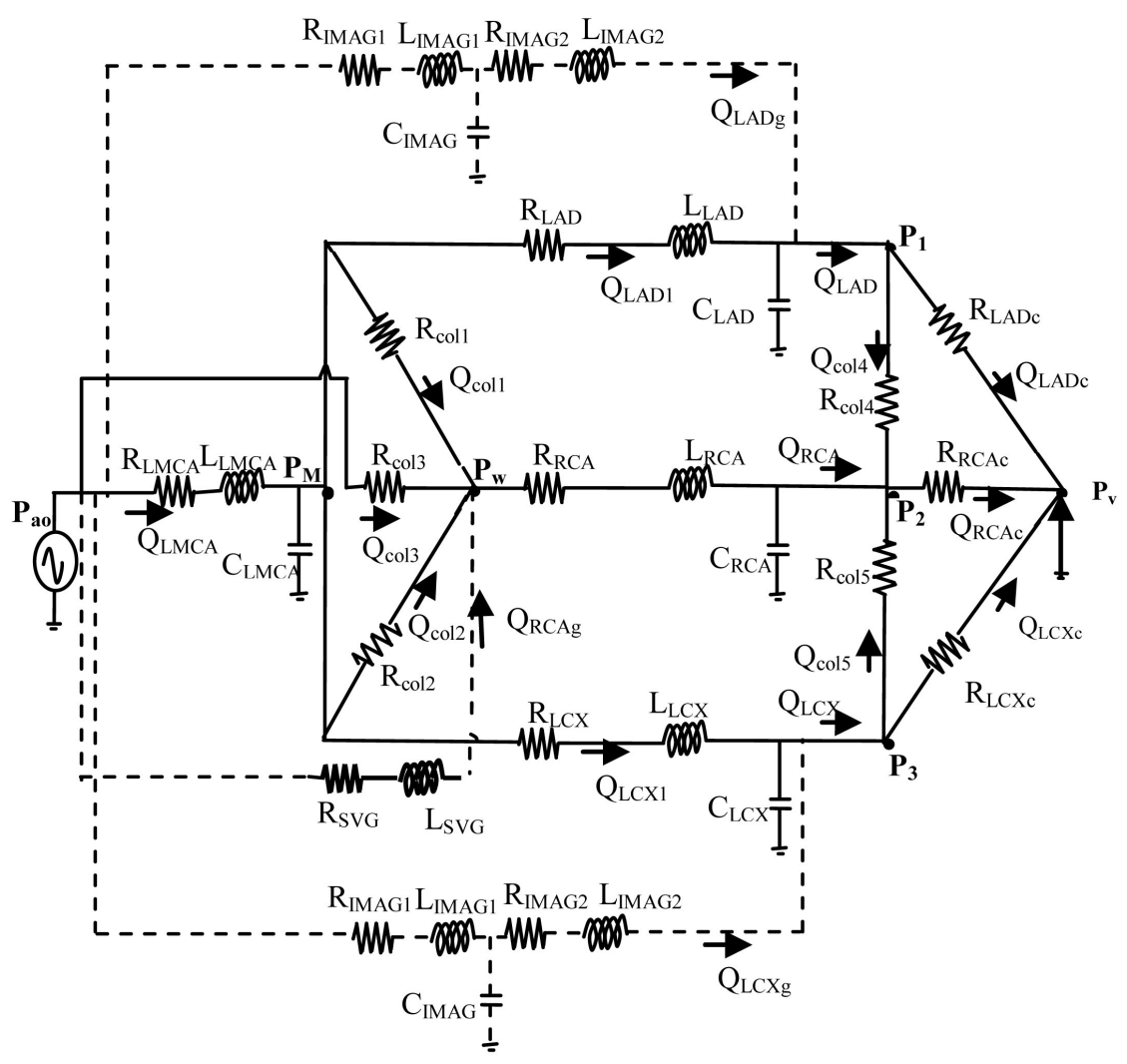

Figure 1. Analog electrical model for the coronary circulation in patients with severe stenoses on LMCA, LAD and LCx, and total occlusion of the right artery. The dotted lines represent the grafts. All the notations are defined in the text (Section 2.2).

capillaries are denoted by $Q_{\mathrm{LADc}}, Q_{\mathrm{LCX}}, Q_{\mathrm{RCAc}}$ respectively. $Q_{\mathrm{col} 11}$ and $Q_{\mathrm{col} 4}$ are the collateral flow rates from LAD towards RCA (before and after LAD stenoses, respectively), $Q_{\text {col2 }}$ and $Q_{\text {col5 }}$ are the collateral flow rates from LCx (before and after LCx stenoses, respectively) and $Q_{\text {col3 }}$ is the ipsilateral collateral flow rate (from the aorta towards the RCA). $P_{\mathrm{M}}$ is the pressure after the LMCA stenosis, $P_{1}$ after the LAD stenosis, $P_{3}$ after the LCX stenosis. $P_{2}$ denotes the pressure at the end of the RCA branch.

Kirchhoffs laws (current law and voltage law) apply to the circuit shown in Figure 1. The current law says that for any junction, the sum of currents flowing into that node is equal to the sum of currents flowing out of that node. The voltage law says that the sum of all the voltages around one loop is equal to zero. For example, this means that the flow rate in the LAD artery, $Q_{\mathrm{LAD}}$, will be the sum of the flow rate in the $\mathrm{LAD}$ graft, $Q_{\mathrm{LADg}}$, (if it exists), and of the flow rate in the stenosed native artery, $Q_{\mathrm{LAD} 1}$. This means also that in the absence of the right graft $\left(Q_{\mathrm{RCAg}}=0\right.$, case $(0 \mathrm{G})$ and $(2 \mathrm{G})$ ), the flow in the right territory $\left(Q_{\mathrm{RCA}}\right.$ and $\left.Q_{\mathrm{RCAc}}\right)$ is provided by the collaterals only... and so on, for any node or loop. It is thus evident that any pressure or flow rate of the network depends on the other.

In order to evaluate the severity of the ischemia in any patient and the benefit of the revascularization, we define and calculate the total flow rate delivered to his heart, $Q_{\mathrm{t}}$, as follows:

$$
Q_{\mathrm{t}}=Q_{\mathrm{LAD}}+Q_{\mathrm{LCX}}+Q_{\mathrm{RCA}}
$$

\subsubsection{Parameter Determination}

1) Vessel resistance, inductance and compliance

As suggested by Wang et al. [16] and Pietrabissa et al. [15], $R, L$ and $C$ can be calculated for each vessel segment as follows: 


$$
\begin{gathered}
R=\frac{128 \mu l}{\pi D^{4}} \\
L=\frac{4 \rho l}{\pi D^{2}} \\
C=\frac{\pi D^{3} l}{4 E h}
\end{gathered}
$$

where $\mu=4 \times 10^{-3} \mathrm{~kg} \cdot \mathrm{m}^{-1} \cdot \mathrm{s}^{-1}$ is the blood viscosity; $\rho=10^{3} \mathrm{~kg} \cdot \mathrm{m}^{-3}$ is the blood density; $E=2 \times 10^{5} \mathrm{~Pa}$ is the Young modulus of the vessel; $I(\mathrm{~m})$ is the vessel length; $D(\mathrm{~m})$ is the vessel diameter and $h(\mathrm{~m})$ is the vessel wall thickness (estimated as: $h=0.08 D$ ).

Table 1 shows the values of $R, L$ and $C$ for the left and right coronary arteries and grafts.

Left coronary stenoses were considered by varying the parameters of specific segments of the net as follows [16]:

$$
\begin{gathered}
R=R_{0} \alpha^{-2} \\
C=C_{0} \alpha^{3 / 2} \\
L=L_{0} \alpha^{-1}
\end{gathered}
$$

where $\alpha=1-p, p$ is the percentage of area reduction of the stenosed vessel. $R_{0}, C_{0}$, and $L_{0}$ are the values when $p=0$. Let us take the example of a 90\% reduction area stenosis: $p=0.9$; then $\alpha=0.1$ and the resistance to flow of this segment is multiplied by 100.

2) Capillary resistances

These resistances ( $R_{\mathrm{LADc}}, R_{\mathrm{LCXc}}$ and $R_{\mathrm{RCAc}}$ ) are patient-specific because they are deduced from the clinical data obtained in the case $(3 \mathrm{G})$ for each patient. When the 3 grafts are operating, the pressure is approximately the same in the left and right coronary vessels and the collateral flows towards the RCA become negligible. Using the averaged values (over time) of all the measured quantities (flow rates and pressures), it is possible to write for the left branches [17]:

$$
P_{1}=P_{\text {ao }}-R_{\mathrm{LADg}} \cdot Q_{\mathrm{LADg}} \text { and } P_{3}=P_{\mathrm{ao}}-R_{\mathrm{LCxg}} \cdot Q_{\mathrm{LCxg}}
$$

with

Table 1. Values of resistance $(R)$, inductance $(L)$, and capacitance $(C)$ for the vessels represented in the model.

\begin{tabular}{cccc}
\hline Vessel type & Resistance $(\mathrm{mmHg} \cdot \mathrm{s} / \mathrm{ml})$ & Inductance $\left(\mathrm{mmHg} \cdot \mathrm{s}^{2} / \mathrm{ml}\right)$ & Capacitance $(\mathrm{ml} / \mathrm{mmHg})$ \\
\hline LMCA & 0.1 & 0.02 & 0.002 \\
LAD & 0.5 & 0.03 & 0.0015 \\
LCx & 0.3 & 0.02 & 0.0011 \\
RCA & 0.3 & 0.02 & 0.0008 \\
IMAGI & 1.4 & 0.08 & 0.0054 \\
IMAGII & 5.3 & 0.17 & \\
SVG & 0.2 & 0.04 & \\
\hline
\end{tabular}




$$
R_{\mathrm{LADg}}=R_{\mathrm{LCxg}}=R_{\mathrm{IMAG} 1}+R_{\mathrm{IMAG} 2}
$$

Since

$$
Q_{\mathrm{LMCA}}=Q_{\mathrm{LAD} 1}+Q_{\mathrm{LCx} 1}
$$

we get:

$$
\frac{\left(P_{\mathrm{ao}}-P_{\mathrm{M}}\right) \alpha_{\mathrm{LMCA}}^{2}}{R_{\mathrm{LMCA} 0}}=\frac{\left(P_{\mathrm{M}}-P_{1}\right) \alpha_{\mathrm{LAD}}^{2}}{R_{\mathrm{LAD} 0}}+\frac{\left(P_{\mathrm{M}}-P_{3}\right) \alpha_{\mathrm{LCx}}^{2}}{R_{\mathrm{LCx} 0}}
$$

Equation (7) indicates that $P_{\mathrm{M}}$ can be calculated as:

$$
P_{\mathrm{M}}=\frac{P_{\mathrm{ao}} \frac{\alpha_{\mathrm{LMCA}}^{2}}{R_{\mathrm{LMCA} 0}}+P_{1} \frac{\alpha_{\mathrm{LAD}}^{2}}{R_{\mathrm{LAD} 0}}+P_{3} \frac{\alpha_{\mathrm{LCx}}^{2}}{R_{\mathrm{LCx} 0}}}{\frac{\alpha_{\mathrm{LMCA}}^{2}}{R_{\mathrm{LMCA} 0}}+\frac{\alpha_{\mathrm{LAD}}^{2}}{R_{\mathrm{LAD} 0}}+\frac{\alpha_{\mathrm{LCx}}^{2}}{R_{\mathrm{LCx} 0}}}
$$

Knowing $P_{1}, P_{3}$ and $P_{\mathrm{M}}$ from Equations (4), (5), (8) and from the clinical measurements of $P_{\text {ao }}, Q_{\mathrm{LADg}}$, $Q_{\mathrm{LCxg}}, \alpha_{\mathrm{LMCA}}, \alpha_{\mathrm{LAD}}, \alpha_{\mathrm{LCx}}$ it is possible to calculate:

$$
Q_{\mathrm{LAD} 1}=\frac{\left(P_{\mathrm{M}}-P_{1}\right) \alpha_{\mathrm{LAD}}^{2}}{R_{\mathrm{LAD} 0}} \text { and } Q_{\mathrm{LCx} 1}=\frac{\left(P_{\mathrm{M}}-P_{3}\right) \alpha_{\mathrm{LCx}}^{2}}{R_{\mathrm{LCx} 0}}
$$

and then:

$$
Q_{\mathrm{LADc}}=Q_{\mathrm{LADg}}+Q_{\mathrm{LAD} 1} \text { and } Q_{\mathrm{LCxc}}=Q_{\mathrm{LCxg}}+Q_{\mathrm{LCx} 1}
$$

Finally, $R_{\mathrm{LADc}}$ and $R_{\mathrm{LCxc}}$ are obtained as:

$$
R_{\mathrm{LADc}}=\frac{\left(P_{\mathrm{ao}}-P_{\mathrm{v}}\right)-R_{\mathrm{LADg}} Q_{\mathrm{LADg}}}{Q_{\mathrm{LADC}}} \text { and } R_{\mathrm{LCxc}}=\frac{\left(P_{\mathrm{ao}}-P_{\mathrm{v}}\right)-R_{\mathrm{LCxg}} Q_{\mathrm{LCxg}}}{Q_{\mathrm{LCxc}}}
$$

For the right branch, the capillary resistance $R_{\mathrm{RCAc}}$ is calculated as:

$$
R_{\mathrm{RCAc}}=\frac{\left(P_{\mathrm{ao}}-P_{\mathrm{v}}\right)-\left(R_{\mathrm{RCAg}}+R_{\mathrm{RCA}}\right) Q_{\mathrm{RCAg}}}{Q_{\mathrm{RCAg}}}
$$

with $R_{\mathrm{RCAg}}=R_{\mathrm{SVG}}$.

Variations of the capillary resistances with time

Even if we focus on cycle-averaged values, the simulations themselves are performed as a function of time since the input data of each simulation is the corresponding $P_{\mathrm{ao}}(t)$. During systole, some collapse of the coronary vessels occurs, due to the ventricular contraction, and the micro-vascular resistances are increased [18]. A mathematical formulation (Equation (13)) has been proposed in Harmouche et al. [19] to describe this variation:

$$
R_{\text {cap }}(t)=\left\{\begin{array}{l}
R_{0}+\delta_{1} R_{0} \sin \left(\frac{\pi t}{t_{\mathrm{s}}}\right) \text { for } 0 \leq t \ll t_{\mathrm{s}} \\
R_{0}+\delta_{2} R_{0} \sin \left(\frac{\pi\left(t-t_{\mathrm{s}}+t_{\mathrm{d}}\right)}{t_{\mathrm{d}}}\right) \text { for } t_{\mathrm{s}} \ll t \ll T
\end{array}\right.
$$

In this equation, $R_{\text {cap }}$ denotes either $R_{\mathrm{LADc}}$ or $R_{\mathrm{LCxc}}$ or $R_{\mathrm{RCAc}}, \delta_{1}$ is the fractional value of amplitude increase in systole and $\delta_{2}$ is the fractional value of amplitude decrease in diastole. $T$ is the heart cycle length, $t_{\mathrm{s}}$ the systolic duration, and $t_{\mathrm{d}}$ the diastolic duration. According to Equation (13), the maximal resistance value $\left(R_{0}+\delta_{1} R_{0}\right)$ would be reached when $t=t_{s} / 2$, and the minimal value $\left(R_{0}-\delta_{2} R_{0}\right)$ when $t=t_{\mathrm{s}}+\left(t_{\mathrm{d}} / 2\right)$. 
The parameter $R_{0}$ is chosen in order to ensure that:

$$
\frac{1}{T} \int_{0}^{T} R_{\text {cap }}(t) \mathrm{d} t=R_{\text {cap }}^{\text {fixed }}
$$

where $R_{\text {cap }}$ "fixed" denotes the capillary resistances calculated through Equations (4) to (12).

However, in patients with very severe coronary disease (as it is the case with patients of this study), the significance of the collapse effect of intramural arteries due to myocardial contraction may be reduced.

3) Collateral resistances

Due to the difficulty of determining the exact characteristics of the collateral pathways, it was assumed that all the collateral resistances are the same:

$$
R_{\mathrm{col} 1}=R_{\mathrm{col} 2}=R_{\mathrm{col} 3}=R_{\mathrm{col} 4}=R_{\mathrm{col} 5}=R_{\mathrm{col}}
$$

This resistance is also specific to each patient.

In the case of RCA occlusion and three vessel disease, the value of $R_{\text {col }}$ is strongly related to the value of pressure $P_{\mathrm{w}}$. Thus, the $P_{\mathrm{w}}$ value measured in case $(2 \mathrm{G})$ is used as a convergence criterion to numerically determine the convenient value of $R_{\text {col }}$ for the patient. The numerical simulations are performed using the Matlab Simulink program. The value of $R_{\mathrm{col}}$ is changed until the calculated $P_{\mathrm{w}}$ value converges towards the clinically measured one.

\subsubsection{Flow Rates and Pressure Simulations}

Once the model parameters are determined, flow and pressure predictions can be performed in any branch of the model and for all surgical cases.

\section{RESULTS AND RELATED DISCUSSION}

\subsection{Medical Informations and Stenoses Severity}

The medical informations collected for all the patients are gathered in Table 2.

The intensity of collateral recipient vessel filling was assessed in accordance with the Rentrop's angiographic grading system: 0 or 1 means poor collaterals, 2 means moderate collaterals, 3 rich collaterals.

Previous ischemic events and myocardial infarction (MI) may have induced microvascular dysfunction and scar tissue. This is an important point since the success of bypass construction depends on the patency of the distal territory of the obstructed arteries [20].

Contrary to Patient 22 who previously received a bare-metal stent (BMS) on LAD, Patient 17 had a subtotal occlusion in the LCx which was treated with a drug eluting stent (DES). He then developed severe intra-sent restenosis, associated with other stenoses and total occlusion of the RCA. Indication to bypass grafting (CABG) was posed.

Left ventricular function (LVEF) or operative risks such as diabetes mellitus $[21,22]$ are also to be considered by the surgeons in their decision to bypass a totally occluded vessel, especially the RCA.

The measured percentages of area reduction are presented in Table 3. Most of the patients have left main lesions with associated distal disease on the LAD and LCX artery. In patients 3,6,8,15, all these stenoses are severe. In Patients 1, 2, 4, 5, 11, 17, 19, 20, 21, the LAD and LCx arteries are severely occluded with no or moderate lesion on LMCA. On the contrary, Patient 7 has no area restriction on LAD and Patients $9,10,12,13,14$ have no area restriction on LCx. Depending on their location, the area restrictions will have a different physiological meaning. Flow to the LAD and LCx arteries will be reduced by any stenosis on LMCA. Conversely, the presence of downstream stenosis in either LAD or LCx increases the resistance distal to LMCA, thereby reducing the maximal blood flow in this segment. The situation seems quite critical for Patients 19 and 21: two arteries totally occluded (RCA and LCx) and LAD almost totally occluded.

\subsection{Clinical Measurements during Surgery}

Pressures and graft flows measured during surgery are presented in Table 4 . In most cases, no 
Table 2. Patient's medical informations.

\begin{tabular}{|c|c|c|c|c|c|}
\hline Patient number & Rentrop Score & $\operatorname{LVEF}(\%)$ & Previous stent? & Previous MI? & Diabetes Mellitus? \\
\hline 1 & 3 & 60 & No & No & No \\
\hline 2 & 2 & 57 & No & Yes & No \\
\hline 3 & 3 & 45 & No & Yes & No \\
\hline 4 & 3 & 67 & No & Yes & No \\
\hline 5 & 3 & 66 & No & No & No \\
\hline 6 & 2 & 46 & No & Yes & No \\
\hline 7 & 3 & 30 & No & No & No \\
\hline 8 & 1 & 60 & No & No & No \\
\hline 9 & 1 & 60 & No & No & No \\
\hline 10 & 2 & 30 & No & No & No \\
\hline 11 & 3 & 70 & No & No & No \\
\hline 12 & 3 & 51 & No & No & Yes \\
\hline 13 & 3 & 66 & No & No & No \\
\hline 14 & 3 & 54 & No & No & No \\
\hline 15 & 3 & 55 & No & No & No \\
\hline 16 & 3 & 45 & No & No & No \\
\hline 17 & 3 & 60 & DES on LCx & No & No \\
\hline 18 & - & 70 & No & No & Yes \\
\hline 19 & - & 55 & No & Yes & No \\
\hline 20 & - & 55 & No & Yes & No \\
\hline 21 & - & 62 & No & Yes & No \\
\hline 22 & - & 60 & BMS on LAD & No & No \\
\hline
\end{tabular}

Table 3. Area reduction (\%) on LMCA, LAD and LCx. All the patients have $100 \%$ obstruction on RCA.

\begin{tabular}{cccc}
\hline Patient number & LMCA & LAD & LCx \\
\hline 1 & 26 & 99.6 & 90.4 \\
2 & 46.7 & 89 & 94.7 \\
3 & 91.6 & 84.8 & 95.6 \\
4 & 19 & 85.6 & 97 \\
5 & 20.8 & 87.7 & 92.1 \\
\hline
\end{tabular}




\begin{tabular}{cccc}
\hline 6 & 85.6 & 93.7 & 82.4 \\
7 & 79.8 & 0 & 84.8 \\
8 & 86.3 & 69.7 & 89.8 \\
9 & 83.2 & 77.9 & 0 \\
10 & 75 & 92.7 & 0 \\
11 & 0 & 75 & 86.3 \\
12 & 75 & 84 & 0 \\
13 & 78.8 & 94.7 & 0 \\
14 & 81.5 & 66.4 & 0 \\
15 & 87.7 & 79.7 & 88.4 \\
16 & 75 & 91 & 100 \\
17 & 0 & 91 & 91 \\
18 & 75 & 75 & 99 \\
19 & 0 & 99 & 100 \\
20 & 19 & 96 & 96 \\
21 & 36 & 96 & 100 \\
22 & 75 & 91 & 91 \\
\hline
\end{tabular}

Table 4. Pressures and graft flows measured during surgery (as explained in Section 2.1). Pressures are in $\mathrm{mmHg}$, flow rates in $\mathrm{ml} / \mathrm{min}$.

\begin{tabular}{cccccccccc}
\hline Patient & $P_{\text {ao }}(0 \mathrm{G})$ & $P_{\mathrm{v}}(0 \mathrm{G})$ & $P_{\mathrm{w}}(0 \mathrm{G})$ & $P_{\mathrm{ao}}(1 \mathrm{G})$ & $P_{\mathrm{v}}(1 \mathrm{G})$ & $Q_{\mathrm{RCAg}}(1 \mathrm{G})$ & $P_{\mathrm{ao}}(2 \mathrm{G})$ & $P_{\mathrm{v}}(2 \mathrm{G})$ & $P_{\mathrm{w}}(2 \mathrm{G})$ \\
\hline 1 & 60 & 3 & 35 & 66 & 2 & 35 & 51 & 0 & 31 \\
2 & 85 & 9 & 49 & 85 & 8 & 45 & 82 & 13 & 49 \\
3 & 85 & 6 & 40 & 85 & 7 & 28 & 80 & 7 & 40 \\
4 & 75 & 9 & 43 & 79 & 10 & 11 & 69 & 10 & 42 \\
5 & 77 & 5 & 53 & 76 & 5 & 63 & 61 & 3 & 36 \\
6 & 78 & 6 & 35 & 65 & 6 & 18 & 70 & 6 & 28 \\
7 & 83 & 14 & 29 & 82 & 14 & 53 & 88 & 14 & 40 \\
8 & 76 & 6 & 46 & 76 & 6 & 9 & 68 & 6 & 43 \\
9 & 70 & 14 & 37 & 70 & 14 & 60 & 70 & 14 & 40 \\
10 & 64 & 10 & 47 & 64 & 10 & 11 & 64 & 10 & 48 \\
11 & 63 & 3 & 33 & 63 & 3 & 15 & 67 & 4 & 33 \\
12 & 89 & 6 & 39 & 89 & 6 & 21 & 84 & 5 & 34 \\
\hline https://doi.org/10.4236/jbise.2021.143014 & & 150 & J. Biomedical Science and Engineering
\end{tabular}




\section{Continued}

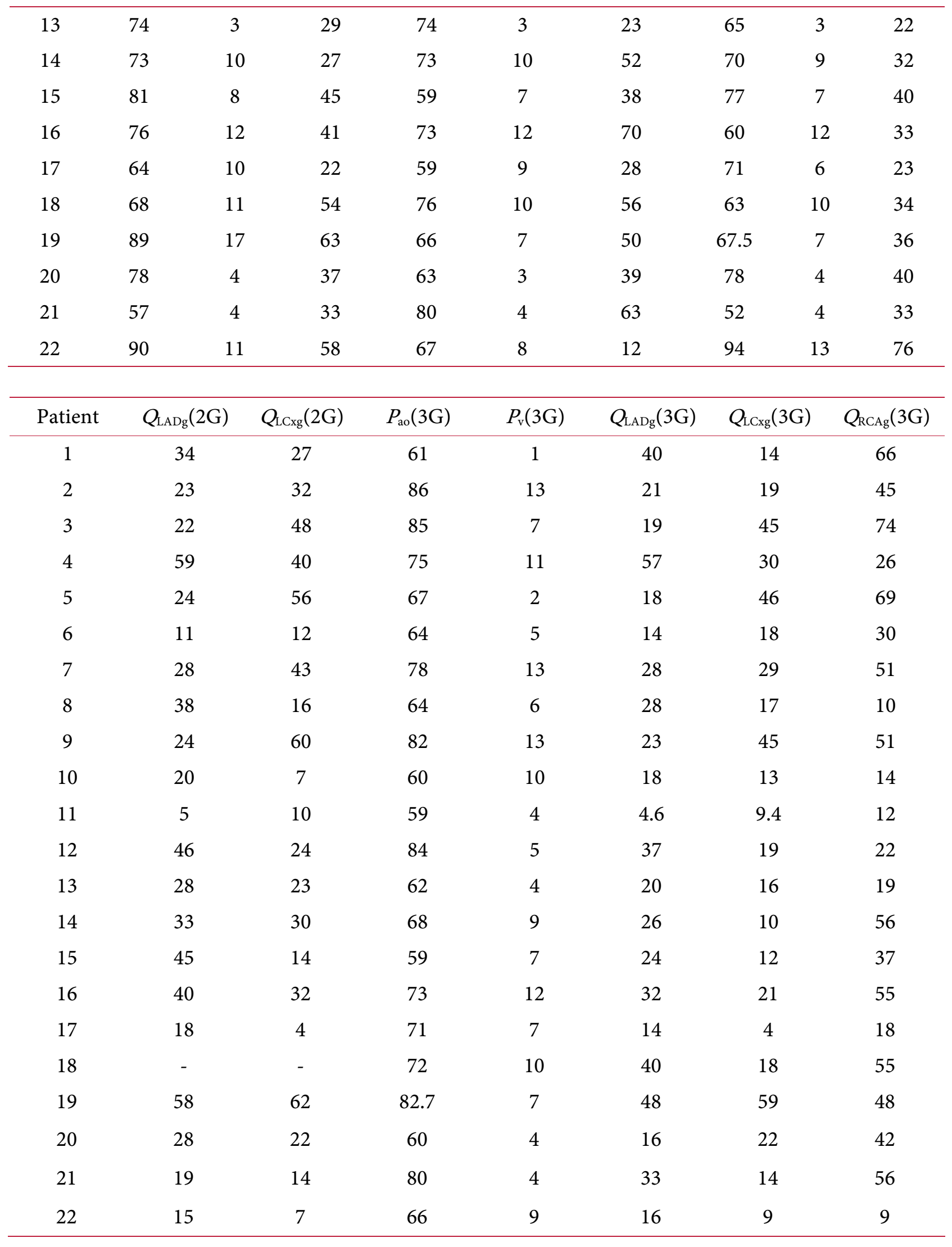


significant variation of the pressure $P_{\mathrm{w}}$ (pressure distal to the RCA thrombosis) was observed after performing left coronary artery bypass grafts $\left(P_{\mathrm{w}}(2 \mathrm{G})\right.$ compared to $\left.P_{\mathrm{w}}(0 \mathrm{G})\right)$. In Patient $5,18,19, P_{\mathrm{w}}(2 \mathrm{G})$ is significantly lower than $P_{\mathrm{w}}(0 \mathrm{G})$ and in Patient 7 and $22, P_{\mathrm{w}}(2 \mathrm{G})$ is higher than $P_{\mathrm{w}}(0 \mathrm{G})$. This may be related to a decrease (or increase) of the collateral flow towards RCA or to the left grafts themselves, or to the status of LAD and LCx distal bed. As a rule, the absence of variation of $P_{\mathrm{w}}$ before and after left coronary artery revascularization suggests that grafting of the occluded right coronary artery remains justified (mean value over the 22 patients: $P_{\mathrm{w}}(0 \mathrm{G})=40.68 \pm 10.49 \mathrm{mmHg}$ and $\left.P_{\mathrm{w}}(2 \mathrm{G})=37.86 \pm 10.92 \mathrm{mmHg}\right)$.

Graft blood flow depends on the gradient of pressure between mean aortic pressure and the pressure present in the distal coronary bed, on the extent of native coronary arterial obstruction, on the size and resistance of the supplied area, on the mechanical properties of the graft itself, on the distal anastomosis... Blood flow through saphenous vein grafts is known to be higher than blood flow through ITA grafts to the same target area [23]. This is the case in most of the patients of this study, except Patient $n^{\circ} 4, n^{\circ} 8, n^{\circ} 22$.

Patients 6,10,11, 17, and 22 have mean graft flows lower than $20 \mathrm{ml} / \mathrm{min}$. As indicated by Takami and Takagi [24], such values may be considered as critically low. Among these patients, we can notice that Patient 6 had a previous myocardial infarction, Patient 10 has low LVEF (30\%), Patient 11 has a Rentrop Score equal to 3, Patient 17 had previously a DES on LCx and Patient 22 had previously a BMS on LAD.

Kaku et al. [25] established an inverse correlation between the Rentrop grade and the flow rates in the Left Internal Thoracic Artery: the higher the Rentrop grade, the lower the flow rates in the graft (Rentrop 0 or 1: mean graft flow $=50.4 \pm 26.3 \mathrm{ml} / \mathrm{min}$; Rentrop 2: $\mathrm{MGF}=43.1 \pm 24.1 \mathrm{ml} / \mathrm{min}$; Rentrop 3: $\mathrm{MGF}=32.6$ $\pm 14.4 \mathrm{ml} / \mathrm{min}$ ). Our data do not follow such a clear trend, and in any case, they are in a slightly lower range of values. Kaku et al. [25] address the question of the competition between graft flow and collateral flow; however, some good collateral circulation may have also preserved left ventricular contractility and patency of the distal segments of obstructed arteries, thereby maintaining conditions which are favorable for the construction of successful coronary bypass grafts.

A decrease in blood flow occurs across the LAD graft, $\Delta Q_{\mathrm{LADg}}$, and across the LCx graft, $\Delta Q_{\mathrm{LCxg}}$, after unclamping the saphenous vein graft implanted on the occluded RCA. The mean values of these drops for the whole group of patients (except Patient 18) are: $\Delta Q_{\mathrm{LADg}}=Q_{\mathrm{LADg}}(2 \mathrm{G})-Q_{\mathrm{LADg}}(3 \mathrm{G})=3.88 \pm 7.22 \mathrm{ml} / \mathrm{min}$, and $\Delta Q_{\mathrm{LCxg}}=Q_{\mathrm{LCxg}}(2 \mathrm{G})-Q_{\mathrm{LCxg}}(3 \mathrm{G})=5.31 \pm 7.28 \mathrm{ml} / \mathrm{min}$. In the situation (3G), all the grafts are operating and the role of the collateral network becomes negligible (because the pressure gradient across the collateral network drops to almost zero). The drops in the grafts $\Delta Q_{\mathrm{LADg}}$ and $\Delta Q_{\mathrm{LCxg}}$ may thus represent the amount of collateral blood flow contributed by the left grafts in the situation (2G) [13].

Borowski et al. [26] provided flow measurements in RCA-graft in case of revascularization of chronically occluded RCA. In diabetic patients, they found $50 \mathrm{ml} / \mathrm{min}$, which corresponds to the values of $Q_{\mathrm{RCAg}}(1 \mathrm{G})$ and $Q_{\mathrm{RCAg}}(3 \mathrm{G})$ for Patient 18 of this study. However, the flow rates measured for Patient 12 (who is diabetic also) are significantly lower (about $20 \mathrm{ml} / \mathrm{min}$ ).

\subsection{Calculated Capillary and Collateral Resistances}

The microvascular resistances were calculated as explained in Section 2.2.1, for each patient. The results are presented in Table 5. An important dispersion of the values can be noticed: from 41.5 to 354.9 $\mathrm{mmHg} \cdot \mathrm{s} / \mathrm{ml}$ for $R_{\mathrm{LADc}}$, from 28.6 to $808.3 \mathrm{mmHg} \cdot \mathrm{s} / \mathrm{ml}$ for $R_{\mathrm{LCxc}}$, from 54 to $379.5 \mathrm{mmHg} \cdot \mathrm{s} / \mathrm{ml}$ for $R_{\mathrm{RCAc}}$, from 165 to $2980 \mathrm{mmHg} \cdot \mathrm{s} / \mathrm{ml}$ for the collateral resistances. In terms of averaged values $(n=22)$, this yields: $R_{\mathrm{LADc}}=152.8 \pm 94.4 \mathrm{mmHg} \cdot \mathrm{s} / \mathrm{ml}, R_{\mathrm{LCxc}}=192.2 \pm 168.8 \mathrm{mmHg} \cdot \mathrm{s} / \mathrm{ml}, R_{\mathrm{RCAc}}=138.7 \pm 96.7$ $\mathrm{mmHg} \cdot \mathrm{s} / \mathrm{ml}$. Excluding the values of Patients $6,8,11,12,13$, and 17, which are clearly out of the normal range, a reference for collateral resistances may be obtained by averaging the values of all the other 16 patients. Such a mean value would be: $R_{\mathrm{col}}=411.6 \pm 128.1 \mathrm{mmHg} \cdot \mathrm{s} / \mathrm{ml}$. Xie et al. [27] adopted a value of 240 $\mathrm{mmHg} \cdot \mathrm{s} / \mathrm{ml}$ for the microvascular resistance distal to a single stenosis. This corresponds to the range of our data.

No clear correlation with previous MI or Rentrop score can be evidenced.

As regards the influence of diabetes mellitus, an elevated value was obtained for the collateral resistance of Patient 12, but this is not the case for Patient 18. This result confirms the conclusion of Zbinden 
Table 5. Values of the capillary and collateral resistances (all in $\mathrm{mmHg} \cdot \mathrm{s} / \mathrm{ml}$ ).

\begin{tabular}{|c|c|c|c|c|}
\hline Patient & $R_{\mathrm{LADc}}$ & $R_{\mathrm{LCX} c}$ & $R_{\mathrm{RCAc}}$ & $R_{\mathrm{col}}$ \\
\hline 1 & 83.3 & 207.8 & 54 & 165 \\
\hline 2 & 174.5 & 210.8 & 96.8 & 430 \\
\hline 3 & 207.4 & 94.1 & 62.7 & 350 \\
\hline 4 & 47.5 & 119.1 & 147.2 & 580 \\
\hline 5 & 175 & 68.7 & 56.0 & 200 \\
\hline 6 & 239.1 & 130.4 & 117.5 & 1085 \\
\hline 7 & 41.5 & 116.2 & 76 & 655 \\
\hline 8 & 73.1 & 190.4 & 347.5 & 1075 \\
\hline 9 & 354.9 & 28.6 & 80.7 & 415 \\
\hline 10 & 155.6 & 49.9 & 213.8 & 405 \\
\hline 11 & 391.2 & 243.6 & 274.5 & 1595 \\
\hline 12 & 101.8 & 57.6 & 215 & 1765 \\
\hline 13 & 165.5 & 58 & 182.7 & 1980 \\
\hline 14 & 67.1 & 392.8 & 62.7 & 495 \\
\hline 15 & 91.9 & 236 & 83.8 & 440 \\
\hline 16 & 97.4 & 167.6 & 66 & 410 \\
\hline 17 & 241.4 & 808.3 & 212.8 & 2980 \\
\hline 18 & 50.8 & 199.7 & 67.1 & 385 \\
\hline 19 & 87.8 & 70.2 & 94.1 & 480 \\
\hline 20 & 199 & 141 & 79.5 & 405 \\
\hline 21 & 128.7 & 319 & 80.9 & 255 \\
\hline 22 & 187.6 & 319.2 & 379.5 & 515 \\
\hline
\end{tabular}

et al. [28], who could not demonstrate any influence of diabetes mellitus on coronary collateral flow.

In Patient 17, remarkably elevated collateral resistance and LCx capillary resistance are observed, pertaining to the LCx artery affected by restenosis of a DES. This suggests deterioration of coronary beds distal to the DES itself, due to the released anti-proliferative drugs [29].

\subsection{Flows in LMCA Branch}

The simulated values for the flows in left main coronary artery, $Q_{\mathrm{LMCA}}$, are gathered in Table 6. High values ( $>115 \mathrm{ml} / \mathrm{min}$ in the case $(0 \mathrm{G})$ ) are found in Patients 7, 9, 12. Each of these patients has at least one artery without blockage (Patient 7: 0\% stenosis on LAD; Patients 9 and 12: 0\% stenosis on LCx), associated with moderate restrictions on the two other segments. Conversely, Patients 17, 19, 21 suffer low perfusion rates $(<21 \mathrm{ml} / \mathrm{min}$ in the case $(0 \mathrm{G}))$. Surprisingly, it seems that this can be related to very severe stenoses on LAD and LCx, but not on LMCA. This provides evidence that the functional impact of the 
Table 6. Flows in LMCA branch (in $\mathrm{ml} / \mathrm{min}$ ).

\begin{tabular}{|c|c|c|c|c|}
\hline Patient & $Q_{\mathrm{LMCA}}(0 \mathrm{G})$ & $Q_{\mathrm{LMCA}}(1 \mathrm{G})$ & $Q_{\mathrm{LMCA}}(2 \mathrm{G})$ & $Q_{\mathrm{LMCA}}(3 \mathrm{G})$ \\
\hline 1 & 40.7 & 14.0 & 18.0 & 2.9 \\
\hline 2 & 50.2 & 32.1 & 14.0 & 4.4 \\
\hline 3 & 48.3 & 26.8 & 11.4 & 3.7 \\
\hline 4 & 71.7 & 63.6 & 21.0 & 16.2 \\
\hline 5 & 84.2 & 49.7 & 25.3 & 9.7 \\
\hline 6 & 47.2 & 31.3 & 12.2 & 7.7 \\
\hline 7 & 129.7 & 113.6 & 71.9 & 56.0 \\
\hline 8 & 68.2 & 62.3 & 18.2 & 15.2 \\
\hline 9 & 116.6 & 101.7 & 58.9 & 64.5 \\
\hline 10 & 80.1 & 70.7 & 50.1 & 41.7 \\
\hline 11 & 27.5 & 22.7 & 12.1 & 7.5 \\
\hline 12 & 125.7 & 119.1 & 65.6 & 61.8 \\
\hline 13 & 84.5 & 79.4 & 43.2 & 38.0 \\
\hline 14 & 73.8 & 56.5 & 28.1 & 19.4 \\
\hline 15 & 65.8 & 34.0 & 17.1 & 7.7 \\
\hline 16 & 37.3 & 20.6 & 10.5 & 3.3 \\
\hline 17 & 17.3 & 13.2 & 4.4 & 2.2 \\
\hline 18 & 70.3 & 63.5 & 31.8 & 26.3 \\
\hline 19 & 13.2 & 0.6 & 7.9 & 0.1 \\
\hline 20 & 36.0 & 14.6 & 13.0 & 1.2 \\
\hline 21 & 20.7 & 7.7 & 9.4 & 0.8 \\
\hline 22 & 37.9 & 21.7 & 8.6 & 3.0 \\
\hline
\end{tabular}

LMCA stenosis strongly depends on the downstream stenoses (LAD and LCx stenosis). Reciprocally, the flow in LMCA will determine the flow in LAD and LCx and in the collateral pathways $Q_{\text {col1 }}$ and $Q_{\text {col2. }}$. Such a hemodynamic interplay between serial stenoses is addressed in the literature by several authors [30, 31].

Besides, a decrease of $Q_{\mathrm{LMCA}}$ can be noticed when the number of operating grafts increases. Averaged values over the whole group of patients yield: $61.2 \pm 33.4 \mathrm{ml} / \mathrm{min}$ in the case $(0 \mathrm{G}), 46.3 \pm 34.5 \mathrm{ml} / \mathrm{min}$ in the case (1G), $25.1 \pm 20.0 \mathrm{ml} / \mathrm{min}$ in the case $(2 \mathrm{G})$ and $17.9 \pm 20.9 \mathrm{ml} / \mathrm{min}$ in the case $(3 \mathrm{G})$. This is not surprising since the presence of the right graft changes the pressure $P_{\mathrm{w}}$ and the presence of the left grafts also increases $P_{1}$ and $P_{3}$. They become close to $P_{\text {ao }}$ because the pressure drop in the graft is small. The pressure $P_{\mathrm{w}}$ impacts $P_{\mathrm{M}}$ through the collateral pathways, and thus it also impacts the flow in LMCA. The pressures $P_{1}$ and $P_{3}$ directly impact the flow in the native stenosed left arteries (because the transtenotic pressure gradient is reduced). 


\subsection{Perfusion of the Left Territory}

Results of the simulations for the flows in LAD (resp. in LCx) are presented in Table 7 (resp. Table 8) and results for the perfusion of capillaries distal to LAD (resp. LCx) are presented in Table 9 (resp. 10). Some striking values for the flow in the native LAD artery $\left(Q_{\mathrm{LAD} 1}\right)$ may be noticed in the initial situation (0G): almost no flow $(<1 \mathrm{ml} / \mathrm{min}$ ) for Patients 1 and 19 , corresponding to very severe LAD stenoses (almost total obstruction), and conversely, the highest flow rate for Patient $7(91.4 \mathrm{ml} / \mathrm{min})$, corresponding to an absence of stenosis. The same remark also applies for the flow in the native LCx artery $\left(Q_{\mathrm{LCx} 1}(0 \mathrm{G})\right)$ : almost no flow $(<1 \mathrm{ml} / \mathrm{min}$ ) for Patients $16,18,19$ and 21 , corresponding to almost $100 \%$ LCx obstruction, and conversely, the highest flow rates ( $>63 \mathrm{ml} / \mathrm{min}$ ) for Patients $9,10,12,13$, corresponding to an absence of stenosis.

Table 7. Flows in LAD branch (in $\mathrm{ml} / \mathrm{min}$ ). In the cases (0G) and (1G), we have: $Q_{\mathrm{LAD} 1}=Q_{\mathrm{LAD}}$, since $Q_{\mathrm{LADg}}=0$.

\begin{tabular}{|c|c|c|c|c|c|c|c|c|}
\hline Patient & $Q_{\mathrm{LAD} 1}(0 \mathrm{G})$ & $Q_{\mathrm{LAD} 1}(1 \mathrm{G})$ & $Q_{\mathrm{LAD} 1}(2 \mathrm{G})$ & $Q_{\mathrm{LADg}}(2 \mathrm{G})$ & $Q_{\mathrm{LAD}}(2 \mathrm{G})$ & $Q_{\mathrm{LAD} 1}(3 \mathrm{G})$ & $Q_{\mathrm{LADg}}(3 \mathrm{G})$ & $Q_{\mathrm{LAD}}(3 \mathrm{G})$ \\
\hline 1 & 0.07 & 0.07 & 0.01 & 39.3 & 39.3 & 0.01 & 38.7 & 38.7 \\
\hline 2 & 23.6 & 19.7 & 3.6 & 23.5 & 27.0 & 3.2 & 20.8 & 24.0 \\
\hline 3 & 20.9 & 16.0 & -1.7 & 28.2 & 26.5 & 2.6 & 19.1 & 21.7 \\
\hline 4 & 56.1 & 56.1 & 14.9 & 54.1 & 69.0 & 15.6 & 56.6 & 72.2 \\
\hline 5 & 25.8 & 18.0 & 4.2 & 21.6 & 25.8 & 3.5 & 17.7 & 21.1 \\
\hline 6 & 11.6 & 8.3 & 0.3 & 17.5 & 17.8 & 0.3 & 14 & 14.3 \\
\hline 7 & 91.4 & 87.2 & 62.8 & 41.4 & 104.2 & 55.6 & 32.7 & 88.3 \\
\hline 8 & 48.0 & 46.9 & 15.8 & 33.2 & 49.0 & 15.3 & 29.4 & 44.7 \\
\hline 9 & 10.6 & 6.5 & -12.1 & 25.1 & 13.0 & -14.6 & 25.4 & 10.8 \\
\hline 10 & 12.0 & 10.6 & 0.3 & 21.6 & 21.9 & 0.3 & 17.9 & 18.2 \\
\hline 11 & 10.2 & 9.0 & 4.8 & 6.0 & 10.8 & 3.7 & 4.6 & 8.3 \\
\hline 12 & 39.7 & 38.3 & 6.0 & 39.5 & 45.5 & 5.9 & 38.0 & 43.9 \\
\hline 13 & 11.8 & 11.1 & 0.1 & 22.7 & 22.8 & 0.1 & 20.1 & 20.1 \\
\hline 14 & 52.2 & 48.8 & 23.0 & 32.4 & 55.5 & 22.8 & 27.0 & 49.7 \\
\hline 15 & 39.1 & 25.7 & 8.3 & 39.0 & 47.3 & 7.5 & 24.3 & 31.8 \\
\hline 16 & 25.0 & 20.8 & 2.7 & 28.4 & 31.1 & 3.3 & 31.6 & 35 \\
\hline 17 & 11.1 & 9.7 & 1.6 & 15.0 & 16.7 & 1.5 & 14.0 & 15.5 \\
\hline 18 & 59.0 & 63.5 & 23.2 & 38.2 & 61.4 & 26.7 & 40.5 & 67.2 \\
\hline 19 & 0.8 & 0.6 & 0.05 & 41.5 & 41.5 & 0.06 & 47.4 & 47.5 \\
\hline 20 & 8.7 & 5.4 & 0.5 & 26.1 & 26.6 & 0.3 & 15.8 & 16.1 \\
\hline 21 & 6.8 & 7.6 & 0.5 & 24.4 & 25.0 & 0.7 & 32.3 & 33.0 \\
\hline 22 & 18.8 & 12.8 & 2.4 & 24.4 & 26.8 & 1.6 & 15.8 & 17.4 \\
\hline
\end{tabular}


Table 8. Flows in $\mathrm{LCx}$ branch (in $\mathrm{ml} / \mathrm{min}$ ). In the cases (0G) and (1G), we have: $Q_{\mathrm{ICx} 1}=Q_{\mathrm{Lcx}}$, since $Q_{\mathrm{ICxg}}=0$.

\begin{tabular}{|c|c|c|c|c|c|c|c|c|}
\hline Patient & $Q_{\mathrm{LCx} 1}(0 \mathrm{G})$ & $Q_{\mathrm{LCxl}}(1 \mathrm{G})$ & $Q_{\mathrm{LCx} 1}(2 \mathrm{G})$ & $Q_{\mathrm{LCxg}}(2 \mathrm{G})$ & $Q_{\mathrm{LCx}}(2 \mathrm{G})$ & $Q_{\mathrm{LCx} 1}(3 \mathrm{G})$ & $Q_{\mathrm{LCxg}}(3 \mathrm{G})$ & $Q_{\mathrm{LCx}}(3 \mathrm{G})$ \\
\hline 1 & 19.8 & 13.8 & 3.4 & 17.4 & 20.8 & 2.8 & 13.7 & 16.5 \\
\hline 2 & 15.4 & 12.4 & 1.3 & 21.9 & 23.2 & 1.1 & 18.8 & 19.9 \\
\hline 3 & 15.0 & 13.8 & 0.6 & 48.4 & 49.0 & 1.4 & 44.4 & 45.8 \\
\hline 4 & 8.0 & 7.5 & 0.5 & 29.9 & 30.5 & 0.5 & 29.7 & 30.2 \\
\hline 5 & 37.4 & 31.7 & 6.2 & 46.0 & 52.1 & 6.1 & 44.9 & 51.0 \\
\hline 6 & 30.6 & 23.4 & 7.4 & 23.0 & 30.4 & 7.5 & 18.6 & 26.1 \\
\hline 7 & 31.2 & 27.6 & 1.1 & 38.8 & 39.9 & 1.0 & 30.5 & 31.5 \\
\hline 8 & 17.6 & 16.3 & -0.06 & 20.1 & 20.1 & 0.1 & 17.4 & 17.5 \\
\hline 9 & 99.5 & 97.7 & 63.8 & 46.5 & 110.3 & 80.5 & 51.4 & 132.0 \\
\hline 10 & 63.3 & 61.0 & 45.6 & 18.8 & 64.5 & 41.9 & 15.8 & 57.8 \\
\hline 11 & 14.9 & 13.7 & 4.7 & 11.7 & 16.4 & 3.8 & 9.4 & 13.2 \\
\hline 12 & 82.7 & 81.1 & 56.4 & 24.5 & 80.9 & 56.1 & 23.3 & 79.4 \\
\hline 13 & 69.9 & 68.6 & 40.7 & 22.0 & 62.7 & 38.1 & 19.5 & 57.6 \\
\hline 14 & 13.1 & 8.6 & -3.7 & 17.1 & 13.4 & -3.1 & 11.8 & 8.7 \\
\hline 15 & 17.8 & 9.8 & -0.5 & 22.3 & 21.9 & 0.5 & 12.3 & 12.7 \\
\hline 16 & 0.01 & 0.01 & 0 & 20.0 & 20.0 & 0 & 20.7 & 20.7 \\
\hline 17 & 4.5 & 3.5 & 0.8 & 4.9 & 5.7 & 0.7 & 4.0 & 4.7 \\
\hline 18 & 0.9 & 0.8 & 0.02 & 19.5 & 19.5 & 0.02 & 17.8 & 17.8 \\
\hline 19 & 0.01 & 0.0002 & 0.0045 & 50.1 & 50.2 & 0 & 58.3 & 58.3 \\
\hline 20 & 13.7 & 9.1 & 1.2 & 33.8 & 35 & 0.8 & 21.7 & 22.5 \\
\hline 21 & 0.0 & 0.0 & 0.0 & 12.9 & 12.9 & 0.0 & 13.7 & 13.8 \\
\hline 22 & 14.3 & 9.1 & 2.1 & 14.7 & 16.8 & 1.4 & 9.0 & 10.4 \\
\hline
\end{tabular}

Table 9. Flows in LAD capillary area (in $\mathrm{ml} / \mathrm{min}$ ).

\begin{tabular}{ccccc}
\hline Patient & $Q_{\mathrm{LADc}}(0 \mathrm{G})$ & $Q_{\mathrm{LADc}}(1 \mathrm{G})$ & $Q_{\mathrm{LADc}}(2 \mathrm{G})$ & $Q_{\mathrm{LADc}}(3 \mathrm{G})$ \\
\hline 1 & 6.8 & 15.4 & 33.6 & 40.1 \\
2 & 20.3 & 21.6 & 22.8 & 24.3 \\
3 & 16 & 18.4 & 20.2 & 22 \\
4 & 54.6 & 58.4 & 66.8 & 72.8 \\
5 & 19.6 & 20.9 & 19 & 21.5 \\
\hline
\end{tabular}




\section{Continued}

\begin{tabular}{|c|c|c|c|c|}
\hline 6 & 10.5 & 9.5 & 15.6 & 14.4 \\
\hline 7 & 87.9 & 87.8 & 100.2 & 88.6 \\
\hline 8 & 46.9 & 47.6 & 47.8 & 44.9 \\
\hline 9 & 7.6 & 7.8 & 9.05 & 11.15 \\
\hline 10 & 12.4 & 13.4 & 19.9 & 18.5 \\
\hline 11 & 9 & 9 & 9.55 & 8.3 \\
\hline 12 & 38.5 & 38.9 & 43.95 & 44 \\
\hline 13 & 11.4 & 12.2 & 21.6 & 20.2 \\
\hline 14 & 48.4 & 49.65 & 51.3 & 50 \\
\hline 15 & 35.7 & 27.1 & 42.8 & 32.1 \\
\hline 16 & 22.6 & 24 & 27.6 & 35.45 \\
\hline 17 & 10.5 & 9.9 & 15.8 & 15.5 \\
\hline 18 & 55 & 65.1 & 57.5 & 67.8 \\
\hline 19 & 3 & 6.7 & 38.1 & 48.1 \\
\hline 20 & 8.6 & 9.5 & 21.4 & 16.3 \\
\hline 21 & 8.1 & 16.8 & 21.15 & 33.75 \\
\hline 22 & 18.6 & 14.4 & 25 & 18.15 \\
\hline
\end{tabular}

Apart from these extreme situations, an important decrease of the flow in the native stenosed arteries ( $Q_{\mathrm{LAD} 1}$ and $Q_{\mathrm{LCx} 1}$ ) can be observed when the left grafts are operating. This phenomenon can be attributed to increased distal pressure induced by the graft, decreasing transtenotic flow. This could promote the development of the native disease in these branches. Although the idea of flow competition between the graft and the native artery is commonly admitted, an accelerated progression of native vessel obstruction after surgical coronary bypass grafting has been well documented [32, 33]. Experimental measurements provided by Stein et al. [34] in a hydrodynamic model of the cardiovascular system confirm this finding: the aorta-coronary bypass eliminates the pressure gradient across the stenotic coronary segment, and this causes a reduction of flow in the native artery, which may accelerate the atherosclerotic process. Besides, low flow in a graft may be due to other causes than competition with the transtenotic flow: for example, high resistance in distal microvessels. Overall, the perfusion of the LAD territory ( $\left.Q_{\mathrm{LAD}}\right)$ and of the LCx territory $\left(Q_{\mathrm{LCX}}\right)$ is improved in the presence of the left grafts, but this improvement remains moderate.

Referring to the network of Figure 1, one can easily deduce from mass conservation laws that:

$$
Q_{\mathrm{LAD}}=Q_{\mathrm{LADg}}+Q_{\mathrm{LAD} 1}=Q_{\mathrm{col} 4}+Q_{\mathrm{LADc}} \text { and } Q_{\mathrm{LCx}}=Q_{\mathrm{LCxg}}+Q_{\mathrm{LCx} 1}=Q_{\mathrm{col} 5}+Q_{\mathrm{LCxc}}
$$

Consequently, in the case of moderate stenoses on LAD (or LCx), and important resistances of the collateral pathway $\left(R_{\mathrm{col} 4}\left(\right.\right.$ or $\left.\left.R_{\mathrm{col} 5}\right)\right)$ and microvascular territory $\left(R_{\mathrm{LADc}}\left(\right.\right.$ or $\left.R_{\mathrm{LCxc}}\right)$ ), blood coming from the graft will preferentially flow through the native artery rather than through the collateral pathway and towards the distal capillaries, because the resistance of the native artery is smaller. We thus obtained a negative $Q_{\mathrm{LAD} 1}$ (Patient 9) or $Q_{\mathrm{LCx} 1}$ (Patient 14) flux. Retrograde flow in the native artery has yet been predicted by some computational works or in vitro experiments $[15,35]$. Besides, backflow is also known to occur 
naturally due to the changes in the relative importance of stenotic resistance against distal capillary resistance between systole and diastole. During systole, in which distal capillary resistance becomes high due to myocardial compression, the stenotic resistance is much less important than distal resistance. This has been illustrated, among others, by Nordgaard et al. [36] who measured LAD and LIMA flow profiles in a porcine model under different rates of LAD occlusion.

As it was already mentioned for the branch flow ( $Q_{\mathrm{LAD}}$ and $Q_{\mathrm{LCX}}$ ), it can be seen from the results of Table 9 and Table 10 that the perfusion of the distal capillary areas of these branches $\left(Q_{\mathrm{LADc}}\right)$ and $\left(Q_{\mathrm{LCxc}}\right)$ is moderately improved in the presence of the left grafts. Averaged values calculated over the 22 patients are as follows (all in $\mathrm{ml} / \mathrm{min}$ ): $Q_{\mathrm{LADc}}(0 \mathrm{G})=25.1 \pm 21.7, Q_{\mathrm{LADc}}(1 \mathrm{G})=26.5 \pm 22.0, Q_{\mathrm{LADc}}(2 \mathrm{G})=33.2 \pm 21.7$, $Q_{\mathrm{LADc}}(3 \mathrm{G})=34.0 \pm 21.4$; and $Q_{\mathrm{LCxc}}(0 \mathrm{G})=24.7 \pm 27.2, Q_{\mathrm{LCxc}}(1 \mathrm{G})=26.0 \pm 26.9, Q_{\mathrm{LCxc}}(2 \mathrm{G})=32.8 \pm 25.8$, $Q_{\mathrm{LCxc}}(3 \mathrm{G})=34.3 \pm 29.9$. This is due to the notable decrease of the flow in native artery when the left grafts are operating, so that the sum of these contributions is not very much improved. The LAD capillary perfusion remains particularly low, even in the case $(3 G)$, for Patient $9\left(Q_{\mathrm{LAD} 1}<0\right)$ and for Patient 11 (flows in the left grafts $<10 \mathrm{ml} / \mathrm{min})$. Very low values of $Q_{\mathrm{LCxc}}$ are also obtained for Patient 14, 17 and 21, in correlation with elevated values of the LCx capillary resistance $\left(R_{\mathrm{LCX}}\right)$.

Table 10. Flows in LCx capillary area (in $\mathrm{ml} / \mathrm{min}$ ).

\begin{tabular}{|c|c|c|c|c|}
\hline Patient & $Q_{\mathrm{LCXx}}(0 \mathrm{G})$ & $Q_{\mathrm{LCxc}}(1 \mathrm{G})$ & $Q_{\mathrm{LCxc}}(2 \mathrm{G})$ & $Q_{\mathrm{LCxc}}(3 \mathrm{G})$ \\
\hline 1 & 13.25 & 16.3 & 14.2 & 16.9 \\
\hline 2 & 13.6 & 15.5 & 18.9 & 20.1 \\
\hline 3 & 15.4 & 21.3 & 43.1 & 46.55 \\
\hline 4 & 9.1 & 12.1 & 28.05 & 30.5 \\
\hline 5 & 36 & 39.3 & 46.1 & 52.3 \\
\hline 6 & 28.4 & 23.8 & 28.2 & 26.2 \\
\hline 7 & 28.25 & 28.7 & 35.9 & 31.8 \\
\hline 8 & 16.7 & 17.2 & 18.8 & 17.6 \\
\hline 9 & 96.3 & 98.9 & 106.7 & 132.8 \\
\hline 10 & 60.9 & 61.4 & 62.4 & 58.05 \\
\hline 11 & 13.8 & 13.8 & 15.2 & 13.2 \\
\hline 12 & 81 & 81.3 & 79.3 & 79.5 \\
\hline 13 & 68.5 & 68.7 & 61.5 & 57.7 \\
\hline 14 & 8.8 & 9 & 9 & 8.8 \\
\hline 15 & 14.3 & 11 & 17.2 & 12.85 \\
\hline 16 & 2.1 & 6.3 & 16.4 & 21 \\
\hline 17 & 3.7 & 3.5 & 4.7 & 4.7 \\
\hline 18 & 2.7 & 7.3 & 15.3 & 18 \\
\hline 19 & 2.4 & 6.4 & 46.95 & 59.1 \\
\hline 20 & 13.2 & 13.3 & 29.9 & 22.8 \\
\hline 21 & 2.4 & 7.9 & 8.7 & 14.1 \\
\hline 22 & 12.9 & 9.8 & 14.9 & 10.5 \\
\hline
\end{tabular}




\subsection{Flows in RCA Branch, and Total Flow, $Q_{\mathrm{t}}$}

Results for blood delivery in the right territory are gathered in Table 11. Flow to this area seems critically low for Patient $6,8,10,11,12,13,17,22$, in the case (0G). In a previous study [17], we demonstrated mathematically that the collateral resistance, $R_{\mathrm{col}}$, and the RCA capillary resistance, $R_{\mathrm{RCAc}}$, are preponderant factors for the perfusion of the right territory, in comparison with the other parameters. Indeed, collateral resistance is abnormally high in Patients $6,8,11,12,13,17$ and RCA capillary resistance is abnormally high for Patients 8 and 22. Patient 17 and 22 had previous stent revascularization. Comparing situations $(0 \mathrm{G})$ and $(2 \mathrm{G})$, data of Table 11 also demonstrate the obvious necessity of the RCA bypass: the left grafts alone do not induce a satisfactory improvement in $Q_{\mathrm{RCA}}$ and $Q_{\mathrm{RCAc}}$. The same remark also applies to the results obtained for the total coronary flow, $Q_{\mathrm{t}}$. The averaged $Q_{\mathrm{t}}$ value (over the 22 patients) is $66.1 \pm 33.1$ $\mathrm{ml} / \mathrm{min}$ in the case $(0 \mathrm{G}), 92.5 \pm 38.6 \mathrm{ml} / \mathrm{min}$ in the case $(1 \mathrm{G}), 83.8 \pm 32.4 \mathrm{ml} / \mathrm{min}$ in the case $(2 \mathrm{G}), 107.6 \pm$ $43.5 \mathrm{ml} / \mathrm{min}$ in the case $(3 \mathrm{G})$. Complete revascularization with the 3 grafts is thus fully justified. However, even in the case (3G), $Q_{\text {total }}$ remains lower than $40 \mathrm{ml} / \mathrm{min}$ in Patients $11,17,22$, due to low flow in the grafts and/or poor status of the distal run-off.

\subsection{Collateral Flows}

Results for collateral flows are presented in Table 12. Collateral blood flow is controlled by two factors: the pressure difference between the feeding artery and the receiving artery and the collateral resistance. The highest flows are obtained for Patient 1 and 5, in the case (0G): they are around $10 \mathrm{ml} / \mathrm{min}$, associated with a pressure gradient $\left(P_{\mathrm{ao}}-P_{\mathrm{w}}\right)$ around $25 \mathrm{mmHg}$. This yields a flow capacity of $0.4 \mathrm{ml} / \mathrm{min} / \mathrm{mmHg}$, that can be compared to the data given by Rockstroh and Brown [37]: $0.68 \mathrm{ml} / \mathrm{min} / \mathrm{mmHg}$. Collateral perfusion is notably low in the cases $(0 \mathrm{G})$ and $(2 \mathrm{G})$ in Patients $6,8,11,12,13,17$ and 22: the sum of all the contributions of the 5 connections, $Q_{\text {colsum }}$, remains lower than $11 \mathrm{ml} / \mathrm{min}$, due to elevated values of $R_{\text {col }}$, or to previous stent implantation. Such a blood supply would not be enough to prevent myocardial ischemia in the right area [38]. In some situations, negative $Q_{\mathrm{col}}$ values are obtained, meaning that the direction of collateral flow is reversed. This happens when the pressure in the left arteries $\left(P_{1}\right.$ or $\left.P_{3}\right)$ is lower than $P_{\mathrm{w}}$, either due to very severe stenoses on LAD and LCx (Patient 1, 18, 19,21), or to the revascularization of the right artery (case $(1 \mathrm{G})$ ). Such reverse collateral flows have already been reported in the literature [39-41]. When the revascularization is complete (Case (3G)), the pressure in both left and right arteries is almost aortic pressure. No more pressure gradient exists and the collateral flows become negligible. Loss of collateral flow after revascularization agrees with the findings of previous studies [25, 42-44].

\subsection{Pressures}

Simulated data for the pressure everywhere in the network are shown in Table 13. In the case (0G), as expected, the highest pressure drops in the left arteries are correlated to the most severe area reductions. This can be noticed for Patients 1, 19, 21, as regards $P_{\text {ao }}-P_{1}$ (pressure drop in LAD) and for Patients 16, $18,19,21$, as regards $P_{\text {ao }}-P_{3}$ (pressure drop in LCx). The right graft (case (1G)) allows to get a pressure level equivalent to aortic pressure in RCA $\left(P_{\mathrm{ao}}(1 \mathrm{G}) \approx P_{\mathrm{w}}(1 \mathrm{G}) \approx P_{2}(1 \mathrm{G})\right)$, but it also modifies the pressures on the left side, due to possible reversed flow in the collateral network. A modification of the aortic pressure itself can also be noticed for Patients $15,18,19,20,21,22$. In the case (2G), pressure drops in LAD $\left(P_{\mathrm{ao}}-P_{1}\right)$ and in $\mathrm{LCx}\left(P_{\mathrm{ao}}-P_{3}\right)$ are about a few $\mathrm{mmHg}$, and correspond to the pressure drop in the internal mammary artery grafts. As discussed in Section 3.2, it appears that the pressure distal to the RCA thrombosis, $P_{\mathrm{w}}$, is not significantly improved by the left grafts. Of course, in the case $(3 \mathrm{G})$, all the pressures reach a level close to the aortic pressure.

It is important to mention that the influence of graft anastomoses and of collaterals is de facto included in these pressure data since the parameters used to build the model are deduced from clinical measurements (with the grafts operating). 
Table 11. Flows in RCA branch and total flow, $Q_{\mathrm{t}}$ (in $\mathrm{ml} / \mathrm{min}$ ).

\begin{tabular}{|c|c|c|c|c|c|c|c|c|}
\hline Patient & $Q_{\mathrm{RCA}}(0 \mathrm{G})$ & $Q_{\mathrm{RCA}}(1 \mathrm{G})$ & $Q_{\mathrm{RCA}}(2 \mathrm{G})$ & $Q_{\mathrm{RCA}}(3 \mathrm{G})$ & $Q_{\mathrm{RCAg}}(1 \mathrm{G})$ & $Q_{\mathrm{RCAg}}(3 \mathrm{G})$ & $Q_{\mathrm{RCAc}}(0 \mathrm{G})$ & $Q_{\mathrm{RCAc}}(1 \mathrm{G})$ \\
\hline 1 & 31.3 & 88.0 & 21.8 & 67.8 & 87.7 & 67.5 & 31.1 & 70.3 \\
\hline 2 & 16.8 & 52.4 & 13.8 & 45.5 & 52.4 & 45.4 & 21.9 & 47.4 \\
\hline 3 & 21.3 & 83.8 & 19.2 & 75.0 & 86.7 & 75.3 & 25.7 & 73.9 \\
\hline 4 & 11.4 & 34.9 & 8.4 & 26.9 & 34.9 & 26.9 & 11.8 & 28 \\
\hline 5 & 31.5 & 85.7 & 22.4 & 70.8 & 85.6 & 70.6 & 39.2 & 75.3 \\
\hline 6 & 7.7 & 31.5 & 6.8 & 30.2 & 31.9 & 30.2 & 11.1 & 30.0 \\
\hline 7 & 11.4 & 55.0 & 12.4 & 51.6 & 56.1 & 52.1 & 17.8 & 53.3 \\
\hline 8 & 4.5 & 13.6 & 3.9 & 10.3 & 14.4 & 10.4 & 6.5 & 12.1 \\
\hline 9 & 11.3 & 43.9 & 11.6 & 52.1 & 46.3 & 53.5 & 17.5 & 41.4 \\
\hline 10 & 7.7 & 18.3 & 6.6 & 14.5 & 19.1 & 14.9 & 9.7 & 15.1 \\
\hline 11 & 3.7 & 13.3 & 3.8 & 12.0 & 13.2 & 12 & 5.9 & 13.1 \\
\hline 12 & 5.2 & 23.8 & 4.9 & 22.2 & 24.1 & 22.3 & 8.1 & 23.1 \\
\hline 13 & 4.4 & 24.5 & 3.8 & 19.1 & 24.7 & 19.2 & 6.3 & 23.2 \\
\hline 14 & 13.4 & 61.0 & 13.3 & 56.4 & 61.9 & 56.6 & 21.6 & 59.8 \\
\hline 15 & 14.7 & 39.5 & 14.4 & 37.5 & 40.9 & 37.7 & 21.6 & 37.0 \\
\hline 16 & 18.6 & 64.4 & 11.8 & 55.7 & 64.5 & 55.7 & 18.8 & 54.9 \\
\hline 17 & 2.4 & 14.3 & 2.9 & 18.0 & 14.3 & 18.0 & 3.8 & 14.0 \\
\hline 18 & 16.1 & 66.7 & 13.2 & 56.0 & 67.3 & 56.2 & 18.4 & 58.5 \\
\hline 19 & 18.7 & 49.9 & 11.8 & 49.4 & 49.9 & 49.4 & 14.1 & 37.4 \\
\hline 20 & 20.4 & 53.3 & 16.9 & 42.6 & 53.3 & 42.5 & 21.0 & 45 \\
\hline 21 & 20.9 & 73.1 & 13.4 & 57.1 & 73 & 57 & 17.2 & 56 \\
\hline 22 & 7.4 & 11.7 & 6.2 & 9.3 & 11.9 & 9.4 & 9.0 & 9.3 \\
\hline Patient & \multicolumn{2}{|c|}{$Q_{\mathrm{RCAc}}(2 \mathrm{G})$} & $Q_{\mathrm{RCAc}}(3 \mathrm{G})$ & $Q_{\mathrm{t}}(0 \mathrm{G})$ & \multicolumn{2}{|c|}{$Q_{\mathrm{t}}(1 \mathrm{G})$} & $\mathrm{Q}_{\mathrm{t}}(2 \mathrm{G})$ & $Q_{\mathrm{t}}(3 \mathrm{G})$ \\
\hline 1 & \multicolumn{2}{|c|}{34.2} & 66 & 51.2 & \multicolumn{2}{|l|}{101.9} & 81.9 & 123 \\
\hline 2 & \multicolumn{2}{|c|}{22.3} & 45 & 55.8 & \multicolumn{2}{|l|}{84.5} & 64.0 & 89.4 \\
\hline 3 & \multicolumn{2}{|c|}{31.5} & 74 & 57.2 & \multicolumn{2}{|l|}{113.6} & 94.8 & 142.5 \\
\hline 4 & \multicolumn{2}{|c|}{13} & 26.0 & 75.5 & \multicolumn{2}{|l|}{98.6} & 107.9 & 129.4 \\
\hline 5 & \multicolumn{2}{|c|}{35.2} & 69 & 94.8 & \multicolumn{2}{|l|}{135.4} & 100.4 & 142.9 \\
\hline 6 & \multicolumn{2}{|c|}{11.2} & 30.0 & 50 & \multicolumn{2}{|l|}{63.2} & 55.0 & 70.6 \\
\hline 7 & \multicolumn{2}{|c|}{20.4} & 51.0 & 134.0 & \multicolumn{2}{|l|}{169.8} & 156.6 & 171.4 \\
\hline 8 & \multicolumn{2}{|c|}{6.4} & 10.0 & 70.0 & \multicolumn{2}{|l|}{76.7} & 73.0 & 72.5 \\
\hline
\end{tabular}




\section{Continued}

\begin{tabular}{ccccccc}
\hline 9 & 19.2 & 51.0 & 121.3 & 148.1 & 134.8 & 194.9 \\
10 & 10.6 & 14.0 & 83.0 & 89.9 & 92.9 & 90.5 \\
11 & 6.3 & 12.0 & 28.7 & 35.9 & 31.0 & 33.6 \\
12 & 8.1 & 22.0 & 127.6 & 143.3 & 131.3 & 145.5 \\
13 & 6.2 & 19.2 & 86.1 & 104.2 & 89.3 & 96.9 \\
14 & 21.9 & 56 & 78.8 & 118.5 & 82.2 & 114.9 \\
15 & 23.6 & 37.0 & 71.6 & 75.0 & 83.6 & 82.0 \\
16 & 18.9 & 55.0 & 43.6 & 85.1 & 62.9 & 111.4 \\
17 & 4.8 & 18.0 & 18.1 & 27.5 & 25.3 & 38.2 \\
18 & 21.3 & 55.1 & 76 & 131 & 94.1 & 141 \\
19 & 18.4 & 48.0 & 19.5 & 50.5 & 103.6 & 155.2 \\
20 & 27.1 & 42.0 & 42.9 & 67.9 & 78.5 & 81.2 \\
21 & 21.4 & 56.0 & 27.7 & 80.8 & 51.3 & 103.8 \\
22 & 9.9 & 9 & 40.5 & 33.6 & 49.9 & 37.2 \\
\hline
\end{tabular}

Table 12. (a) Collateral flows (in $\mathrm{ml} / \mathrm{min}$ ). Case (0G); (b) Collateral flows (in $\mathrm{ml} / \mathrm{min}$ ). Case (1G); (c) Collateral flows (in $\mathrm{ml} / \mathrm{min}$ ). Case (2G); (d) Collateral flows (in $\mathrm{ml} / \mathrm{min}$ ). Case (3G).

(a)

\begin{tabular}{cccccc}
\hline Patient & $Q_{\text {col1 }}(0 \mathrm{G})$ & $Q_{\text {col3 }}(0 \mathrm{G})$ & $Q_{\text {col } 4}(0 \mathrm{G})$ & $Q_{\text {col5 }}(0 \mathrm{G})$ & $Q_{\text {colsum }}(0 \mathrm{G})$ \\
\hline 1 & 10.4 & 10.5 & -6.75 & 6.55 & 31.1 \\
2 & 5.6 & 5.65 & 3.3 & 1.8 & 21.95 \\
3 & 6.2 & 8.9 & 4.9 & -0.4 & 25.8 \\
4 & 3.8 & 3.8 & 1.5 & -1.1 & 11.8 \\
5 & 10.5 & 10.6 & 6.2 & 1.4 & 39.2 \\
6 & 2.5 & 2.8 & 1.1 & 2.2 & 11.1 \\
7 & 3.6 & 4.2 & 3.5 & 2.95 & 17.85 \\
8 & 1.3 & 1.8 & 1.1 & 0.9 & 6.4 \\
9 & 3.3 & 4.7 & 3.0 & 3.2 & 17.5 \\
10 & 2.4 & 2.9 & -0.4 & 2.4 & 9.7 \\
11 & 1.2 & 1.2 & 1.2 & 1.1 & 5.9 \\
12 & 1.7 & 1.8 & 1.2 & 1.7 & 8.1 \\
13 & 1.4 & 1.6 & 0.4 & 1.4 & 6.2 \\
14 & 4.3 & 4.9 & 3.8 & 4.3 & 21.6 \\
\hline
\end{tabular}




\section{Continued}

\begin{tabular}{cccccc}
\hline 15 & 4.4 & 5.8 & 3.4 & 3.5 & 21.5 \\
16 & 6.1 & 6.3 & 2.4 & -2.1 & 18.8 \\
17 & 0.8 & 0.8 & 0.6 & 0.8 & 3.8 \\
18 & 5.3 & 5.7 & 4.0 & -1.8 & 18.5 \\
19 & 6.2 & 6.2 & -2.2 & -2.4 & 14 \\
20 & 6.8 & 6.8 & 0.1 & 0.5 & 21 \\
21 & 7.0 & 7.0 & -1.3 & -2.4 & 17.3 \\
22 & 2.4 & 2.6 & 0.2 & 1.4 & 9 \\
\hline
\end{tabular}

(b)

\begin{tabular}{|c|c|c|c|c|c|}
\hline Patient & $Q_{\mathrm{col} 1}(1 \mathrm{G})$ & $Q_{\mathrm{col} 3}(1 G)$ & $Q_{\mathrm{col} 4}(1 \mathrm{G})$ & $Q_{\mathrm{col} 5}(1 \mathrm{G})$ & $Q_{\text {colsum }}(1 G)$ \\
\hline 1 & 0.1 & 0.01 & -15.3 & -2.5 & -17.6 \\
\hline 2 & -0.01 & 0.02 & -1.9 & -3.1 & -5.0 \\
\hline 3 & -1.5 & 0.05 & -2.4 & -7.5 & -12.85 \\
\hline 4 & -0.01 & 0.01 & -2.3 & -4.6 & -6.9 \\
\hline 5 & 0.03 & 0.08 & -2.9 & -7.6 & -10.4 \\
\hline 6 & -0.2 & 0.01 & -1.2 & -0.4 & -2.0 \\
\hline 7 & -0.6 & 0.02 & -0.6 & -1.1 & -2.9 \\
\hline 8 & -0.4 & 0 & -0.7 & -0.9 & -2.4 \\
\hline 9 & -1.2 & 0.02 & -1.3 & -1.2 & -4.9 \\
\hline 10 & -0.4 & 0.01 & -2.8 & -0.4 & -4.0 \\
\hline 11 & 0 & 0 & -0.04 & -0.1 & -0.1 \\
\hline 12 & -0.15 & 0 & -0.6 & -0.2 & -1.1 \\
\hline 13 & -0.1 & 0 & -1.1 & -0.1 & -1.4 \\
\hline 14 & -0.4 & 0.02 & -0.85 & -0.4 & -2.0 \\
\hline 15 & -0.7 & 0.02 & -1.4 & -1.2 & -4.0 \\
\hline 16 & -0.08 & 0.03 & -3.2 & -6.3 & -9.6 \\
\hline 17 & 0 & 0 & -0.2 & -0.04 & -0.2 \\
\hline 18 & -0.3 & 0.03 & -1.6 & -6.5 & -8.7 \\
\hline 19 & 0.02 & 0.02 & -6.1 & -6.4 & -12.4 \\
\hline 20 & 0.02 & 0.03 & -4.1 & -4.2 & -8.2 \\
\hline 21 & 0.05 & 0.06 & -9.2 & -7.9 & -17.0 \\
\hline 22 & -0.1 & 0.005 & -1.6 & -0.7 & -2.5 \\
\hline
\end{tabular}


(c)

\begin{tabular}{|c|c|c|c|c|c|}
\hline Patient & $Q_{\mathrm{col1}}(2 \mathrm{G})$ & $Q_{\mathrm{col} 3}(2 \mathrm{G})$ & $Q_{\mathrm{col} 4}(2 \mathrm{G})$ & $Q_{\mathrm{col} 5}(2 \mathrm{G})$ & $Q_{\text {colsum }}(2 \mathrm{G})$ \\
\hline 1 & 7.3 & 7.3 & 5.7 & 6.6 & 34.2 \\
\hline 2 & 4.6 & 4.6 & 4.2 & 4.3 & 22.3 \\
\hline 3 & 6.2 & 6.8 & 6.3 & 5.9 & 31.4 \\
\hline 4 & 2.8 & 2.8 & 2.2 & 2.45 & 13.05 \\
\hline 5 & 7.5 & 7.5 & 6.8 & 6.0 & 35.3 \\
\hline 6 & 2.25 & 2.3 & 2.2 & 2.2 & 11.2 \\
\hline 7 & 4.0 & 4.4 & 4.0 & 4.0 & 20.4 \\
\hline 8 & 1.3 & 1.4 & 1.2 & 1.3 & 6.5 \\
\hline 9 & 3.65 & 4.35 & 3.95 & 3.6 & 19.2 \\
\hline 10 & 2.1 & 2.4 & 2.0 & 2.1 & 10.7 \\
\hline 11 & 1.3 & 1.3 & 1.25 & 1.2 & 6.35 \\
\hline 12 & 1.6 & 1.7 & 1.55 & 1.6 & 8.05 \\
\hline 13 & 1.2 & 1.3 & 1.2 & 1.2 & 6.1 \\
\hline 14 & 4.4 & 4.6 & 4.2 & 4.4 & 22 \\
\hline 15 & 4.7 & 5.0 & 4.5 & 4.7 & 23.6 \\
\hline 16 & 3.9 & 4.0 & 3.5 & 3.6 & 18.9 \\
\hline 17 & 1.0 & 1.0 & 0.9 & 1.0 & 4.9 \\
\hline 18 & 4.35 & 4.5 & 3.9 & 4.2 & 21.3 \\
\hline 19 & 3.9 & 3.9 & 3.4 & 3.25 & 18.35 \\
\hline 20 & 5.6 & 5.6 & 5.2 & 5.1 & 27.1 \\
\hline 21 & 4.5 & 4.5 & 3.85 & 4.2 & 21.55 \\
\hline 22 & 2.1 & 2.1 & 1.8 & 1.9 & 10 \\
\hline
\end{tabular}

(d)

\begin{tabular}{cccccc}
\hline Patient & $Q_{\text {col1 }}(3 \mathrm{G})$ & $Q_{\text {col3 }}(3 \mathrm{G})$ & $Q_{\text {col } 1}(3 \mathrm{G})$ & $Q_{\text {col5 }}(3 \mathrm{G})$ & $Q_{\text {colsum }}(3 \mathrm{G})$ \\
\hline 1 & 0.1 & 0.1 & -1.4 & -0.4 & -1.5 \\
2 & 0.02 & 0.02 & -0.3 & -0.2 & -0.44 \\
3 & -0.16 & 0.04 & -0.3 & -0.75 & -1.33 \\
4 & 0 & 0.01 & -0.6 & -0.3 & -0.89 \\
5 & 0.06 & 0.07 & -0.4 & -1.3 & -1.51 \\
6 & -0.04 & 0.01 & -0.07 & -0.1 & -0.24 \\
7 & -0.3 & 0.02 & -0.3 & -0.3 & -1.18 \\
\hline
\end{tabular}




\section{Continued}

\begin{tabular}{cccccc}
\hline 8 & -0.1 & 0 & -0.2 & -0.1 & -0.5 \\
9 & -0.7 & 0.03 & -0.35 & -0.8 & -2.52 \\
10 & -0.2 & 0.01 & -0.3 & -0.25 & -0.94 \\
11 & 0 & 0 & -0.02 & -0.04 & -0.06 \\
12 & -0.08 & 0 & -0.1 & -0.08 & -0.34 \\
13 & -0.06 & 0 & -0.06 & -0.06 & -0.24 \\
14 & -0.14 & 0.02 & -0.3 & -0.1 & -0.66 \\
15 & -0.15 & 0.02 & -0.3 & -0.15 & -0.73 \\
16 & 0.01 & 0.03 & -0.45 & -0.3 & -0.7 \\
17 & 0 & 0 & -0.03 & -0.01 & -0.04 \\
18 & -0.1 & 0.03 & -0.6 & -0.2 & -0.97 \\
19 & 0.02 & 0.02 & -0.6 & -0.8 & -1.34 \\
20 & 0.02 & 0.02 & -0.2 & -0.3 & -0.44 \\
21 & 0.04 & 0.04 & -0.75 & -0.3 & -0.93 \\
22 & -0.01 & 0.004 & -0.2 & -0.1 & -0.32 \\
\hline
\end{tabular}

Table 13. Pressure values (in $\mathrm{mmHg}$ ).

\begin{tabular}{ccccccccc}
\hline Patient & $P_{\text {ао }}(0 \mathrm{G})$ & $P_{\mathrm{M}}(0 \mathrm{G})$ & $P_{\mathrm{w}}(0 \mathrm{G})$ & $P_{1}(0 \mathrm{G})$ & $P_{2}(0 \mathrm{G})$ & $P_{3}(0 \mathrm{G})$ & $P_{\text {ао }}(1 \mathrm{G})$ & $P_{\mathrm{M}}(1 \mathrm{G})$ \\
\hline 1 & 60 & 59.8 & 31.1 & 12.5 & 31 & 49 & 66 & 65.9 \\
2 & 85 & 84.5 & 44.4 & 68 & 44.4 & 57 & 84.9 & 84.7 \\
3 & 85 & 69 & 33 & 61.4 & 32.9 & 30.3 & 84.9 & 76.1 \\
4 & 75 & 74.7 & 38 & 52.3 & 37.9 & 27.0 & 79 & 78.7 \\
5 & 77 & 76.6 & 41.7 & 62.3 & 41.6 & 46.2 & 76 & 75.8 \\
6 & 78 & 72.7 & 27.7 & 47.9 & 27.7 & 67.7 & 65 & 61.4 \\
7 & 83 & 75.6 & 36.6 & 74.8 & 36.6 & 68.8 & 81.9 & 75.5 \\
8 & 76 & 67.5 & 43.5 & 63.1 & 43.4 & 59.1 & 76 & 68.2 \\
9 & 70 & 60.3 & 37.6 & 58.5 & 37.5 & 59.8 & 69.9 & 61.5 \\
10 & 64 & 61 & 44.6 & 42.1 & 44.6 & 60.6 & 64 & 61.3 \\
11 & 63 & 62.9 & 30.2 & 61.5 & 30.2 & 58.9 & 63 & 62.9 \\
12 & 89 & 84.2 & 35 & 71.3 & 35 & 83.8 & 88.9 & 84.5 \\
13 & 74 & 69.5 & 22.1 & 34.4 & 22 & 69.2 & 73.9 & 69.8 \\
14 & 73 & 67.9 & 32.6 & 64.1 & 32.5 & 67.8 & 72.9 & 69.1 \\
\hline
\end{tabular}




\section{Continued}

\begin{tabular}{|c|c|c|c|c|c|c|c|c|}
\hline 15 & 81 & 70.7 & 38.2 & 62.8 & 38.2 & 64.1 & 59 & 53.7 \\
\hline 16 & 76 & 74.6 & 32.7 & 48.8 & 32.7 & 18 & 73 & 71.7 \\
\hline 17 & 64 & 63.9 & 23.4 & 52.5 & 23.4 & 61.1 & 59 & 58.9 \\
\hline 18 & 68 & 65.4 & 31.7 & 57.5 & 31.6 & 20 & 76 & 73.6 \\
\hline 19 & 89 & 89 & 39.1 & 21.4 & 39.1 & 19.8 & 66 & 66 \\
\hline 20 & 78 & 77.9 & 31.9 & 32.5 & 31.8 & 35.1 & 63 & 63 \\
\hline 21 & 57 & 56.9 & 27.2 & 21.5 & 27.2 & 16.9 & 80 & 80 \\
\hline 22 & 90 & 88.6 & 67.8 & 69.2 & 67.8 & 79.8 & 67 & 66.2 \\
\hline Patient & $P_{\mathrm{w}}(1 \mathrm{G})$ & $P_{1}(1 \mathrm{G})$ & $P_{2}(1 \mathrm{G})$ & $P_{3}(1 \mathrm{G})$ & $P_{\text {aо }}(2 \mathrm{G})$ & $P_{\mathrm{M}}(2 \mathrm{G})$ & $P_{\mathrm{w}}(2 \mathrm{G})$ & $P_{1}(2 \mathrm{G})$ \\
\hline 1 & 65.7 & 23.3 & 65.3 & 58.4 & 51 & 50.9 & 30.9 & 46.6 \\
\hline 2 & 84.8 & 70.8 & 84.5 & 62.5 & 81.9 & 81.8 & 49 & 79.3 \\
\hline 3 & 84.6 & 70.3 & 84.3 & 40.5 & 79.9 & 76.2 & 40.0 & 76.8 \\
\hline 4 & 78.8 & 56.3 & 78.7 & 34 & 69 & 68.9 & 41.9 & 62.9 \\
\hline 5 & 75.7 & 65.8 & 75.3 & 50 & 61 & 60.9 & 36 & 58.5 \\
\hline 6 & 64.8 & 43.7 & 64.7 & 57.7 & 70 & 68.6 & 28 & 68 \\
\hline 7 & 81.8 & 74.8 & 81.5 & 69.5 & 87.9 & 83.8 & 39.9 & 83.3 \\
\hline 8 & 75.9 & 63.9 & 75.8 & 60.4 & 68 & 65.7 & 43 & 64.2 \\
\hline 9 & 69.8 & 60.4 & 69.6 & 61.1 & 69.9 & 65.1 & 39.9 & 67.2 \\
\hline 10 & 63.9 & 44.7 & 63.8 & 61.0 & 64 & 62.1 & 48 & 61.6 \\
\hline 11 & 62.9 & 61.7 & 62.9 & 59.2 & 67 & 66.9 & 32.9 & 66.3 \\
\hline 12 & 88.9 & 72 & 88.8 & 84.1 & 83.9 & 81.5 & 34 & 79.5 \\
\hline 13 & 73.9 & 36.7 & 73.8 & 69.5 & 65 & 62.7 & 22 & 62.4 \\
\hline 14 & 72.7 & 65.5 & 72.5 & 69 & 70 & 68 & 32 & 66.3 \\
\hline 15 & 58.8 & 48.4 & 58.7 & 50 & 77 & 74.3 & 40 & 72.6 \\
\hline 16 & 72.2 & 50.8 & 72.5 & 29.6 & 60 & 59.6 & 32.9 & 56.8 \\
\hline 17 & 58.9 & 48.9 & 58.8 & 56.8 & 71 & 70.9 & 23 & 69.3 \\
\hline 18 & 75.8 & 65.2 & 75.5 & 34.1 & 63 & 61.8 & 33.9 & 58.7 \\
\hline 19 & 65.8 & 16.8 & 65.6 & 14.5 & 67.5 & 67.5 & 36 & 62.8 \\
\hline 20 & 62.8 & 34.7 & 62.6 & 34.4 & 78 & 78 & 40 & 75.1 \\
\hline 21 & 79.8 & 40.2 & 79.5 & 46 & 52 & 51.9 & 32.9 & 49.3 \\
\hline 22 & 67 & 53 & 66.9 & 60.6 & 94 & 93.7 & 75.9 & 91.2 \\
\hline
\end{tabular}




\begin{tabular}{|c|c|c|c|c|c|c|c|c|}
\hline Patient & $P_{2}(2 \mathrm{G})$ & $P_{3}(2 \mathrm{G})$ & $P_{\text {aо }}(3 \mathrm{G})$ & $P_{\mathrm{M}}(3 \mathrm{G})$ & $P_{\mathrm{w}}(3 \mathrm{G})$ & $P_{1}(3 \mathrm{G})$ & $P_{2}(3 \mathrm{G})$ & $P_{3}(3 \mathrm{G})$ \\
\hline 1 & 30.8 & 49.0 & 61 & 60.9 & 60.7 & 56.6 & 60.4 & 59.4 \\
\hline 2 & 48.9 & 79.5 & 85.9 & 85.9 & 85.8 & 83.6 & 85.6 & 83.9 \\
\hline 3 & 39.9 & 74.5 & 84.9 & 83.7 & 84.7 & 82.8 & 84.4 & 80 \\
\hline 4 & 41.9 & 65.6 & 75 & 74.9 & 74.9 & 68.6 & 74.7 & 71.6 \\
\hline 5 & 35.9 & 55.8 & 67 & 66.9 & 66.7 & 65 & 66.4 & 62 \\
\hline 6 & 27.9 & 67.4 & 64 & 63.1 & 63.9 & 62.4 & 63.7 & 61.9 \\
\hline 7 & 39.9 & 83.6 & 78 & 74.8 & 77.8 & 74.3 & 77.6 & 74.5 \\
\hline 8 & 43 & 65.7 & 64 & 62.1 & 63.9 & 60.7 & 63.9 & 62.0 \\
\hline 9 & 39.8 & 64.8 & 81.9 & 76.6 & 81.8 & 79.1 & 81.5 & 76.2 \\
\hline 10 & 47.9 & 61.9 & 60 & 58.4 & 59.9 & 58 & 59.8 & 58.2 \\
\hline 11 & 32.9 & 65.7 & 59 & 58.9 & 58.9 & 58.4 & 58.9 & 57.9 \\
\hline 12 & 34 & 81.2 & 83.9 & 81.6 & 83.9 & 79.7 & 83.8 & 81.3 \\
\hline 13 & 22 & 62.5 & 62 & 60 & 61.9 & 59.7 & 61.8 & 59.8 \\
\hline 14 & 31.9 & 68.1 & 68 & 66.6 & 67.8 & 65 & 67.5 & 66.6 \\
\hline 15 & 39.9 & 74.4 & 59 & 57.8 & 58.8 & 56.2 & 58.7 & 57.6 \\
\hline 16 & 32.8 & 57.7 & 72.9 & 72.7 & 72.8 & 69.4 & 72.5 & 70.6 \\
\hline 17 & 23 & 70.4 & 71 & 70.9 & 70.9 & 69.4 & 70.8 & 70.5 \\
\hline 18 & 33.8 & 60.9 & 72 & 71 & 71.8 & 67.4 & 71.6 & 70.1 \\
\hline 19 & 35.9 & 61.9 & 82.7 & 82.7 & 82.5 & 77.3 & 82.3 & 76.2 \\
\hline 20 & 40 & 74.3 & 60 & 60 & 59.9 & 58.2 & 59.7 & 57.6 \\
\hline 21 & 32.9 & 50.6 & 80 & 80 & 79.8 & 76.4 & 79.6 & 78.5 \\
\hline 22 & 75.9 & 92.4 & 66 & 65.9 & 66 & 64.2 & 65.9 & 65.1 \\
\hline
\end{tabular}

\subsection{Distal to Proximal Pressure Ratios}

Distal to proximal pressure ratios for LMCA, LAD and LCx stenoses may be easily obtained from the computed pressure values of Table 13. These ratios are presented in Table 14, for all the situations (0G, $1 \mathrm{G}, 2 \mathrm{G}, 3 \mathrm{G})$.

Considering the impact of the LMCA stenosis, all values are above 0.8 . The lowest value $(0.81)$ is obtained in Patient 3, case (0G), and corresponds to the highest area restriction (92\%). Obviously, this does not reflect the quite low LMCA flow rates shown for Patients 17, 19, 21 in Table 6. The pressure ratio alone cannot allow concluding that there is no ischemia in the distal territory, because perfusion through one stenosis is also influenced by the other stenoses, and by the microcirculatory resistances.

The correlation between stenosis severity, low flow rates and low pressure ratios seems more evident in LAD and LCx branches. Patients 1, 19, 20, 21 have LAD area reductions higher than $96 \%$, transtenotic flow rates $\left(Q_{\mathrm{LADl}}(0 \mathrm{G})\right)$ lower than $10 \mathrm{ml} / \mathrm{min}$, and pressure ratios $P_{1} / P_{\mathrm{M}}(0 \mathrm{G})$ lower than 0.42 . Patients 4,16 , $18,19,21$ have LCx area reductions higher than $97 \%$, transtenotic flow rates $\left(Q_{\mathrm{LCxl}}(0 \mathrm{G})\right)$ lower than $10 \mathrm{ml} / \mathrm{min}$, 
Table 14. Pressure ratios (no units). Case (0G); (b) Pressure ratios (no units). Case (1G); (c) Pressure ratios (no units). Case (2G); (d) Pressure ratios (no units). Case (3G).

(a)

\begin{tabular}{|c|c|c|c|c|c|}
\hline Patient & $P_{\mathrm{M}} / P_{\mathrm{ao}}(0 \mathrm{G})$ & $P_{1} / P_{\mathrm{M}}(0 \mathrm{G})$ & $P_{3} / P_{\mathrm{M}}(0 \mathrm{G})$ & $P_{1} / P_{\mathrm{ao}}(0 \mathrm{G})$ & $P_{3} / P_{\mathrm{ao}}(0 \mathrm{G})$ \\
\hline 1 & 0.997 & 0.209 & 0.819 & 0.208 & 0.817 \\
\hline 2 & 0.994 & 0.804 & 0.674 & 0.8 & 0.671 \\
\hline 3 & 0.812 & 0.89 & 0.439 & 0.722 & 0.356 \\
\hline 4 & 0.996 & 0.7 & 0.361 & 0.697 & 0.36 \\
\hline 5 & 0.995 & 0.813 & 0.603 & 0.81 & 0.6 \\
\hline 6 & 0.932 & 0.659 & 0.932 & 0.614 & 0.869 \\
\hline 7 & 0.91 & 0.99 & 0.911 & 0.901 & 0.829 \\
\hline 8 & 0.888 & 0.935 & 0.876 & 0.83 & 0.777 \\
\hline 9 & 0.862 & 0.97 & 0.992 & 0.836 & 0.855 \\
\hline 10 & 0.953 & 0.691 & 0.995 & 0.658 & 0.948 \\
\hline 11 & 0.998 & 0.978 & 0.937 & 0.977 & 0.935 \\
\hline 12 & 0.947 & 0.846 & 0.995 & 0.801 & 0.942 \\
\hline 13 & 0.94 & 0.495 & 0.995 & 0.466 & 0.935 \\
\hline 14 & 0.93 & 0.943 & 0.999 & 0.878 & 0.929 \\
\hline 15 & 0.873 & 0.888 & 0.906 & 0.775 & 0.791 \\
\hline 16 & 0.981 & 0.654 & 0.242 & 0.642 & 0.237 \\
\hline 17 & 0.999 & 0.821 & 0.956 & 0.82 & 0.955 \\
\hline 18 & 0.961 & 0.88 & 0.306 & 0.846 & 0.294 \\
\hline 19 & 0.998 & 0.241 & 0.223 & 0.24 & 0.223 \\
\hline 20 & 0.998 & 0.418 & 0.451 & 0.417 & 0.45 \\
\hline 21 & 0.998 & 0.377 & 0.296 & 0.377 & 0.296 \\
\hline 22 & 0.984 & 0.782 & 0.9 & 0.769 & 0.887 \\
\hline
\end{tabular}

(b)

\begin{tabular}{cccccc}
\hline Patient & $P_{\mathrm{M}} / P_{\text {aо }}(1 \mathrm{G})$ & $P_{1} / P_{\mathrm{M}}(1 \mathrm{G})$ & $P_{3} / P_{\mathrm{M}}(1 \mathrm{G})$ & $P_{1} / P_{\text {aо }}(1 \mathrm{G})$ & $P_{3} / P_{\text {aо }}(1 \mathrm{G})$ \\
\hline 1 & 0.998 & 0.353 & 0.886 & 0.353 & 0.885 \\
2 & 0.997 & 0.836 & 0.738 & 0.834 & 0.736 \\
3 & 0.896 & 0.924 & 0.532 & 0.828 & 0.477 \\
4 & 0.996 & 0.715 & 0.432 & 0.713 & 0.43 \\
5 & 0.997 & 0.868 & 0.66 & 0.866 & 0.658 \\
\hline
\end{tabular}




\section{Continued}

\begin{tabular}{cccccc}
\hline 6 & 0.946 & 0.712 & 0.939 & 0.673 & 0.888 \\
7 & 0.921 & 0.99 & 0.921 & 0.912 & 0.848 \\
8 & 0.898 & 0.937 & 0.886 & 0.842 & 0.796 \\
9 & 0.88 & 0.982 & 0.992 & 0.864 & 0.873 \\
10 & 0.959 & 0.73 & 0.995 & 0.699 & 0.954 \\
11 & 0.999 & 0.981 & 0.942 & 0.98 & 0.941 \\
12 & 0.95 & 0.852 & 0.995 & 0.81 & 0.945 \\
13 & 0.944 & 0.526 & 0.995 & 0.497 & 0.939 \\
14 & 0.947 & 0.948 & 0.999 & 0.898 & 0.946 \\
15 & 0.91 & 0.903 & 0.932 & 0.822 & 0.848 \\
16 & 0.983 & 0.708 & 0.412 & 0.697 & 0.405 \\
17 & 0.999 & 0.830 & 0.963 & 0.83 & 0.963 \\
18 & 0.969 & 0.885 & 0.463 & 0.857 & 0.449 \\
19 & 1 & 0.254 & 0.22 & 0.254 & 0.219 \\
20 & 0.999 & 0.551 & 0.546 & 0.551 & 0.545 \\
21 & 0.999 & 0.503 & 0.575 & 0.502 & 0.574 \\
22 & 0.988 & 0.801 & 0.915 & 0.791 & 0.904 \\
\hline
\end{tabular}

(c)

\begin{tabular}{cccccc}
\hline Patient & $P_{\mathrm{M}} / P_{\text {aо }}(2 \mathrm{G})$ & $P_{1} / P_{\mathrm{M}}(2 \mathrm{G})$ & $P_{3} / P_{\mathrm{M}}(2 \mathrm{G})$ & $P_{1} / P_{\text {ао }}(2 \mathrm{G})$ & $P_{3} / P_{\text {aо }}(2 \mathrm{G})$ \\
\hline 1 & 0.998 & 0.915 & 0.962 & 0.914 & 0.96 \\
2 & 1 & 0.969 & 0.972 & 0.968 & 0.971 \\
3 & 0.954 & 1.0 & 0.978 & 0.961 & 0.932 \\
4 & 0.998 & 0.913 & 0.952 & 0.912 & 0.951 \\
5 & 0.998 & 0.962 & 0.917 & 0.96 & 0.916 \\
6 & 0.98 & 0.991 & 0.982 & 0.972 & 0.963 \\
7 & 0.953 & 0.994 & 0.997 & 0.948 & 0.951 \\
8 & 0.967 & 0.978 & 1 & 0.945 & 0.967 \\
9 & 0.93 & 1.03 & 0.995 & 0.96 & 0.926 \\
10 & 0.971 & 0.991 & 0.996 & 0.962 & 0.967 \\
11 & 0.999 & 0.991 & 0.981 & 0.99 & 0.981 \\
12 & 0.971 & 0.976 & 0.996 & 0.948 & 0.967 \\
13 & 0.965 & 0.996 & 0.997 & 0.961 & 0.962 \\
14 & 0.973 & 0.975 & 1 & 0.948 & 0.973 \\
\hline
\end{tabular}




\section{Continued}

\begin{tabular}{cccccc}
\hline 15 & 0.965 & 0.977 & 1.0 & 0.943 & 0.968 \\
16 & 0.993 & 0.953 & 0.969 & 0.947 & 0.963 \\
17 & 1.0 & 0.977 & 0.992 & 0.976 & 0.992 \\
18 & 0.981 & 0.95 & 0.985 & 0.932 & 0.966 \\
19 & 1.0 & 0.931 & 0.918 & 0.931 & 0.917 \\
20 & 0.999 & 0.963 & 0.953 & 0.962 & 0.952 \\
21 & 0.999 & 0.948 & 0.974 & 0.947 & 0.973 \\
22 & 0.997 & 0.974 & 0.987 & 0.97 & 0.983 \\
\hline
\end{tabular}

(d)

\begin{tabular}{|c|c|c|c|c|c|}
\hline Patient & $P_{\mathrm{M}} / P_{\mathrm{ao}}(3 \mathrm{G})$ & $P_{1} / P_{\mathrm{M}}(3 \mathrm{G})$ & $P_{3} / P_{\mathrm{M}}(3 \mathrm{G})$ & $P_{1} / P_{\text {ao }}(3 \mathrm{G})$ & $P_{3} / P_{\text {aо }}(3 \mathrm{G})$ \\
\hline 1 & 0.998 & 0.929 & 0.975 & 0.928 & 0.973 \\
\hline 2 & 1 & 0.973 & 0.977 & 0.973 & 0.977 \\
\hline 3 & 0.986 & 0.989 & 0.956 & 0.975 & 0.942 \\
\hline 4 & 0.999 & 0.916 & 0.956 & 0.915 & 0.955 \\
\hline 5 & 0.999 & 0.971 & 0.926 & 0.971 & 0.925 \\
\hline 6 & 0.986 & 0.989 & 0.981 & 0.976 & 0.968 \\
\hline 7 & 0.959 & 0.994 & 0.997 & 0.954 & 0.956 \\
\hline 8 & 0.97 & 0.978 & 0.999 & 0.949 & 0.97 \\
\hline 9 & 0.935 & 1.033 & 0.995 & 0.966 & 0.93 \\
\hline 10 & 0.974 & 0.993 & 0.996 & 0.967 & 0.97 \\
\hline 11 & 1.0 & 0.992 & 0.982 & 0.991 & 0.982 \\
\hline 12 & 0.972 & 0.977 & 0.997 & 0.95 & 0.969 \\
\hline 13 & 0.968 & 0.996 & 0.997 & 0.964 & 0.965 \\
\hline 14 & 0.981 & 0.975 & 1 & 0.956 & 0.981 \\
\hline 15 & 0.98 & 0.974 & 0.997 & 0.954 & 0.977 \\
\hline 16 & 0.997 & 0.955 & 0.971 & 0.952 & 0.968 \\
\hline 17 & 1.0 & 0.978 & 0.994 & 0.978 & 0.994 \\
\hline 18 & 0.986 & 0.95 & 0.987 & 0.937 & 0.973 \\
\hline 19 & 1 & 0.935 & 0.921 & 0.935 & 0.921 \\
\hline 20 & 1 & 0.97 & 0.96 & 0.97 & 0.96 \\
\hline 21 & 1 & 0.955 & 0.982 & 0.954 & 0.981 \\
\hline 22 & 0.998 & 0.974 & 0.987 & 0.973 & 0.985 \\
\hline
\end{tabular}


and pressure ratios $P_{3} / P_{\mathrm{M}}(0 \mathrm{G})$ lower than 0.36 . Absence of stenosis (Patient 7 (no stenosis on LAD); Patients $9,10,12,13$ (no stenosis on LCx)) is also correlated with high flow rates and pressure ratios higher than 0.99 . The results obtained for Patient 14 have to be studied more carefully: no stenosis on LCx, $P_{3} / P_{\mathrm{M}}(0 \mathrm{G})$ very close to 1 , and a surprisingly low flow rate $\left(Q_{\mathrm{LCx} 1}=13 \mathrm{ml} / \mathrm{min}\right)$. This may be due to the status of the distal run-off: for Patient 14, the $R_{\mathrm{LCxc}}$ value $(393 \mathrm{mmHg} \cdot \mathrm{s} / \mathrm{ml})$ is about 6 times higher than the $R_{\mathrm{LADc}}$ value (67 mmHg.s/ml); consequently, blood flows much more easily into LAD.

Pressure ratios $P_{1} / P_{\text {ao }}$ or $P_{3} / P_{\text {ao }}$ combine the influence of the successive stenoses: LMCA stenosis + LAD stenosis $\left(P_{1} / P_{\text {ao }}=\left(P_{\mathrm{M}} / P_{\text {ao }}\right) *\left(P_{1} / P_{\mathrm{M}}\right)\right)$ or LMCA stenosis $+\mathrm{LCx}$ stenosis $\left(P_{3} / P_{\text {ao }}=\left(P_{\mathrm{M}} / P_{\mathrm{ao}}\right) *\left(P_{3} / P_{\mathrm{M}}\right)\right)$. So that each stenosis may independently have a pressure ratio higher than 0.8 , but the product is lower than 0.8. For example: in Patient $3, P_{\mathrm{M}} / P_{\mathrm{ao}}(0 \mathrm{G})=0.81, P_{1} / P_{\mathrm{M}}(0 \mathrm{G})=0.89$ and $P_{1} / P_{\text {ao }}=0.72$; in Patient 8, $P_{\mathrm{M}} / P_{\text {ao }}(0 \mathrm{G})=0.89, P_{3} / P_{\mathrm{M}}(0 \mathrm{G})=0.87$ and $P_{3} / P_{\text {ao }}=0.78$; in Patient $15, P_{\mathrm{M}} / P_{\text {aо }}(0 \mathrm{G})=0.87, P_{1} / P_{\mathrm{M}}(0 \mathrm{G})=0.89$ and $P_{1} / P_{\text {ao }}=0.77$.

Other groups already pointed out that the individual pressure ratio of a stenosis gets affected by the presence of other lesions or by the resistance of the supplied myocardium area $[4,7,30,31,45,46]$.

When the right graft is operating (case $(1 \mathrm{G})$ ), all the ratios increase slightly, because the pressures are modified even in the left branches. But, except for the LAD artery of Patient 3 and for both LAD and LCx of Patient 15, values that were previously lower than 0.8 remain lower than 0.8 .

In the case $(2 \mathrm{G})$ and $(3 \mathrm{G})$, all the ratios become higher than 0.91 because the pressure drops in the grafts $\left(P_{\text {ao }}-P_{1}\right.$ or $\left.P_{\text {ao }}-P_{3}\right)$ are small (a few mmHg). The highest scores are obtained in the case (3G), demonstrating again that complete revascularization is fully justified for the 3-vessel disease patients of this study. For Patient 9, the previously mentioned situation with retrograde flow through the LAD stenosis $\left(Q_{\mathrm{LAD} 1}<0\right)$ corresponds to $P_{1}>P_{\mathrm{M}}$, i.e. $P_{1} / P_{\mathrm{M}}>1$.

\section{LIMITATIONS OF THE MODEL}

There are two main limitations:

- $\quad$ Taking the same $R_{\text {col }}$ value for the five collateral pathways is an approximation; determining a specific value for each pathway, or at least, some proportions between these collateral resistances, would make the model closer to the physiology.

- The capillary resistances, $R_{\mathrm{LADc}}, R_{\mathrm{LCxc}}, R_{\mathrm{RCAc}}$, are deduced for each patient from the measurements performed with the 3 grafts operating. These values are also used to perform the simulations in the $0 \mathrm{G}$, $1 \mathrm{G}, 2 \mathrm{G}$ situations. This is another approximation of our model and probably does not represent exactly the physiology.

A way to estimate the impact of these approximations is to calculate the relative error (ER) between simulated and measured values of the same quantity when it is possible. If ER is defined as

$$
\mathrm{ER}=(\text { simulated value }- \text { clinical value }) / \text { clinical value, }
$$

we obtain (averaged values over all the patients): $16.5 \%$ for $P_{\mathrm{w}}(0 \mathrm{G}), 0.1 \%$ for $P_{\mathrm{w}}(2 \mathrm{G}), 20.8 \%$ for $Q_{\mathrm{LADg}}(2 \mathrm{G})$, $38.4 \%$ for $Q_{\mathrm{LCxg}}(2 \mathrm{G}), 2.45 \%$ for $Q_{\mathrm{LADg}}(3 \mathrm{G}), 5.8 \%$ for $Q_{\mathrm{LCxg}}(3 \mathrm{G}), 48.2 \%$ for $Q_{\mathrm{RCAg}}(1 \mathrm{G}), 2.2 \%$ for $Q_{\mathrm{RCAg}}(3 \mathrm{G})$, thus showing that the model fails to reproduce satisfactorily the flow rates $Q_{\mathrm{LCxg}}(2 \mathrm{G})$ and $Q_{\mathrm{RCAg}}(1 \mathrm{G})$.

However, the values of the parameters (resistances, inductances, compliances) used to run our calculations, and the influence of the lumen restriction on these values are in good agreement with those given by Uus et al. [47] who constructed a 0D coronary blood flow model from Coronary Computed Tomography datasets.

\section{CONCLUSIONS}

This paper demonstrates that for patients with stenoses on LAD, LCx, LMCA and occlusion of the RCA, the flow rate delivered to the right territory is of course a function of the aortic pressure, the left stenoses severity, and the pressure distal to the thrombosis, but it mainly depends on the capillary and collateral resistances, and the proportion between them. In any case, the collateral supply remains low and 
the improvement in myocardial flow resulting from bypass graft exceeds significantly provided by collateral circulation.

Our simulations allow knowing pressures and flows everywhere in the coronary network. It thus appears that abnormal microvascular hemodynamics, may be present in patients with nonhemodynamic significant lesions as assessed by the pressure ratio. The simultaneous analysis of flow and pressure is necessary to distinguish the impact of the focal stenosis from that of downstream coronary resistance. Consequently, a surgical decision based on pressure measurements only may miss some real hemodynamic problems due to the considered stenosis. This risk is even greater in case of serial stenoses.

Besides, quantitative values of different parameters (for example, the capillary resistances) based on physiological measurements are provided, which may also be used for further developments (3D computational models).

\section{ACKNOWLEDGEMENTS}

The authors would like to thank Dr Majid Harmouche, Dr Issam Abouliatim, and Pr Vito-Giovanni Ruggieri who also participated in this study in the past. And Dr Mahmoud Maasrani, from the Lebanese University, Tripoli, Lebanon.

\section{FUNDING}

This research did not receive any specific grant from funding agencies in the public, commercial, or not-for-profit sectors.

\section{AUTHOR'S CONTRIBUTIONS}

Drs Amédéo Anselmi, Hervé Corbineau, Jean-Philippe Verhoye are surgeons. They described the problem studied, collected the clinical data, analyzed the results, and contributed to writing the paper. Agnès Drochon is a physicist. She designed the electric analog model, analyzed the results and proposed a paper draft.

\section{CONFLICTS OF INTEREST}

The authors declare that they have no competing financial interests or personal relationships that could have influenced the work reported in this paper.

\section{REFERENCES}

1. Pijls, N., Van Son, J.A., Kirkeeide, R.L., De Bruyne, B. and Gould, K.L. (1993) Experimental Basis of Determining Maximum Coronary, Myocardial, and Collateral Blood Flow by Pressure Measurements for Assessing Functional Stenosis Severity before and after Percutaneous Transluminal Coronary Angioplasty. Circulation, 87, 1354-1367. https://doi.org/10.1161/01.CIR.87.4.1354

2. Abuouf, Y., Ookawara, S. and Ahmed, M. (2020) Analysis of the Effect of Guidewire Position on Stenosis Diagnosis Using Computational Fluid Dynamics. Computers in Biology and Medicine, 121, Article ID: 103777. https://doi.org/10.1016/j.compbiomed.2020.103777

3. Taylor, Ch., Fonte, T. and Min, J. (2013) Computational Fluid Dynamics Applied to Cardiac Computed Tomography for Noninvasive Quantification of Fractional Flow Reserve: Scientific Basis. Journal of the American College of Cardiology, 61, 2233-2241. https://doi.org/10.1016/j.jacc.2012.11.083

4. Morris, P., Van De Vosse, F., Lawford, P., Hose, R. and Gunn, J. (2015) Virtual (Computed) Fractional Flow Reserve, Current Challenges and limitations. JACC: Cardiovascular Interventions, 8, 1009-1017. https://doi.org/10.1016/j.jcin.2015.04.006

5. Freiman, M., Nickisch, H., Schmitt, H., Maurovich-Horvat, P., Donnelly, P., Vembar, M. and Goshen, L. (2018) 
A Functionally-Personalized Boundary Condition Model to Improve Estimates of Fractional Flow Reserve with CT (CT-FFR). Medical Physicss, 45, 1170-1177. https://doi.org/10.1002/mp.12753

6. Fayssal, I., Moukalled, F., Alam, S. and Isma'eel, H. (2018) An Outflow Boundary Condition Model for Noninvasive Prediction of Fractional Flow Reserve in Diseased Coronary Arteries. Journal of Biomechanical Engineering, 140, Article ID: 041004 (13 p.). https://doi.org/10.1115/1.4038250

7. Garcia, D., Harbaoui, B., Van De Hoef, T., Meuwissen, M., Nijjer, S., Echavarria-Pinto, M., Davies, J., Piek, J. and Lantelme, P. (2019) Relationship between FFR, CFR and Coronary Microvascular Resistance-Practical Implications for FFR-Guided Percutaneous Coronary Intervention. PLoS ONE, 14, e0208612. https://doi.org/10.1371/journal.pone.0208612

8. Quarteroni, A. and Veneziani, A. (2003) Analysis of a Geometrical Multiscale Model Based on the Coupling of ODEs and PDEs for Blood Flow Simulations. Multiscale Modeling \& Simulation, 1, 173-195. https://doi.org/10.1137/S1540345902408482

9. Olufsen, M. and Nadim, A. (2004) On Deriving Lumped Models for Blood Flow and Pressure in the Systemic Arteries. Mathematical Biosciences and Engineering, 1, 61-80. https://doi.org/10.3934/mbe.2004.1.61

10. Maasrani, M., Verhoye, J., Corbineau, H. and Drochon, A. (2008) Analog Electrical Model of the Coronary Circulation in Case of Multiple Revascularizations. Annals of Biomedical Engineering, 36, 1163-1174. https://doi.org/10.1007/s10439-008-9500-5

11. Maasrani, M., Abouliatim, I., Harmouche, M., Verhoye, J., Corbineau, H. and Drochon, A. (2011) Patients' Specific Simulations of Coronary Fluxes in Case of Three-Vessel Disease. Journal of Biomedical Science and Engineering, 4, 34-45. https://doi.org/10.4236/jbise.2011.41005

12. Verhoye, J., De La Tour, B., Drochon, A. and Corbineau, H. (2005) Collateral Flow Reserve and Right Coronary Occlusion: Evaluation during Off-Pump Revascularization. Interactive CardioVascular and Thoracic Surgery, 4, 23-26. https://doi.org/10.1510/icvts.2004.093088

13. Verhoye, J., Abouliatim, I., Drochon, A., De La Tour, B., Leclerq, Ch., Leguerrier, A. and Corbineau, H. (2007) Collateral Blood Flow between Left Coronary Artery Bypass Grafts And chronically Occluded Right Coronary Circulation in Patients with Triple Vessel disease. European Journal of Cardio-Thoracic Surgery, 31, 49-54. https://doi.org/10.1016/j.ejcts.2006.09.033

14. Morris, P., Soto, D., Feher, J., Rafiroiu, D., Lungu, A., Varma, S., Lawford, P., Hose, R. and Gunn, J. (2017) Fast Virtual Fractional Flow Reserve Based upon Steady-State Computational Fluid Dynamics Analysis. Results from the VIRTU-Fast Study. JACC: Basic to Translational Science, 2, 434-446.

https://doi.org/10.1016/j.jacbts.2017.04.003

15. Pietrabissa, R., Mantero, S., Marotta, T. and Menicanti, L. (1996) A Lumped Parameter Model to Evaluate the Fluid Dynamics of Different Coronary Bypasses. Medical Engineering and Physics, 18, 477-484.

https://doi.org/10.1016/1350-4533(96)00002-1

16. Wang, J.Z., Tie, B., Welkowitz, W., Kostis, J. and Semmlow, J. (1989) Incremental Network Analogue Model of the Coronary Artery. Medical and Biological Engineering and Computing, 27, 416-422. https://doi.org/10.1007/BF02441434

17. Harmouche, M., Maasrani, M., Verhoye, J., Corbineau, H. and Drochon, A. (2014) Coronary Three-Vessel Disease with Occlusion of the Right Coronary Artery: What Are the Most Important Factors That Determine the Right Territory Perfusion? IRBM, 35, 149-157. https://doi.org/10.1016/j.irbm.2013.11.002

18. Spaan, J., Kolyva, C., Van Der Wijngaard, J., Ter Wee, R., Van Horssen, P., Piek, J. and Siebes, M. (2008) Coronary Structure and Perfusion in Health and Disease. Philosophical Transactions of the Royal Society A, 366, 3137-3153. https://doi.org/10.1098/rsta.2008.0075

19. Harmouche, M., Anselmi, A., Maasrani, M., Mariano, Ch., Corbineau, H., Verhoye, J. and Drochon, A. (2014) 
Coronary Three Vessel Disease Hydrodynamics: Simulations Including the Time-Dependence of the Microvascular Resistances. Advances in Biomechanics and Applications, 1, 279-292.

https://doi.org/10.12989/aba.2014.1.4.279

20. Nijveldt, R., Beek, A., Hirsch, A., Stoel, M., Hofman, M., Umans, V., Algra, P., Twisk, J. and Van Rossum, A. (2008) Functional Recovery after Acute Myocardial Infarction: Comparison between Angiography, Electrocardiography, and Cardiovascular Magnetic Resonance Measures of Microvascular Injury. Journal of the American College of Cardiology, 52, 181-189. https://doi.org/10.1016/j.jacc.2008.04.006

21. Marcheix, B., Van den Eynden, F., Demers, P., Bouchard, D. and Cartier, R. (2008) Influence of Diabetes Mellitus on Long-Term Survival in Systematic Off-Pump Coronary Artery Bypass Surgery. Annals of Thoracic Surgery, 86, 1181-1188. https://doi.org/10.1016/j.athoracsur.2008.06.063

22. Wit, M., De Mulder, M., Jansen, E. and Umans, V. (2013) Diabetes Mellitus and Its Impact on Long-Term Outcomes after Coronary Artery Bypass Graft Surgery. Acta Diabetologica, 50, 123-128.

https://doi.org/10.1007/s00592-010-0223-3

23. Schmitz, C., Ashraf, O., Schiller, W., Preusse, Cl., Esmailzadeh, B., Likungu, J.A., Fimmers, R. and Welz, A. (2003) Transit Time Flow Measurement in On-Pump and Off-Pump Coronary Artery Surgery. Journal of Thoracic and Cardiovascular Surgery, 126, 645-650. https://doi.org/10.1016/S0022-5223(03)00018-7

24. Takami, Y. and Takagi, Y. (2018) Roles of Transit Time Flow Measurement for Coronary Artery Bypass Surgery. Journal of Thoracic and Cardiovascular Surgery, 66, 426-433. https://doi.org/10.1055/s-0037-1618575

25. Kaku, D., Nakahira, A., Hirai, H., Sasaki, Y., Hosono, M., Bito, Y., Suehiro, Y. and Suehiro, S. (2013) Does Rich Coronary Collateral Circulation Distal to Chronically Occluded Left Anterior Descending Artery Compete with Graft Flow? Interactive Cardio Vascular and Thoracic Surgery, 17, 944-949. https://doi.org/10.1093/icvts/ivt337

26. Borowski, A., Godehardt, E. and Dalyanoglu, H. (2017) Surgical Decision Making for Revascularization of Chronically Occluded Right Coronary Artery. General Thoracic and Cardiovascular Surgery, 65, 17-24. https://doi.org/10.1007/s11748-016-0702-8

27. Xie, X., Zheng, M., Wen, D., Li, Y. and Xie, S. (2018) A New CFD Based Non-Invasive Method for Functional Diagnosis of Coronary Stenosis. BioMedical Engineering OnLine, 17, Article No. 36. https://doi.org/10.1186/s12938-018-0468-6

28. Zbinden, R., Zbinden, S., Billinger, M., Windecker, S., Meier, B. and Seiler, C. (2005) Influence of Diabetes Mellitus on Coronary Collateral Flow: An Answer to an Old Controversy. Heart, 91, 1289-1293. https://doi.org/10.1136/hrt.2004.041236

29. Meier, P., Zbinden, R., Togni, M., Wenaweser, P., Windecker, S., Meier, B. and Seiler, C. (2007) Coronary Collateral Function Long after Drug-Eluting stent Implantation. Journal of the American College of Cardiology, 49, 15-20. https://doi.org/10.1016/j.jacc.2006.08.043

30. Coppel, R., Lagache, M., Finet, G., Rioufol, G., Gomez, A., Derimay, F., Malvé, M., Yazdani, S., Pettigrew, R. and Ohayon, J. (2019) Influence of Collaterals on True FFR Prediction for a Left Main Stenosis with Concomitant lesions: An in Vitro Study. Annals of Biomedical Engineering, 47, 1409-1421. https://doi.org/10.1007/s10439-019-02235-y

31. Modi, B., Sankaran, S., Kim, H., Ellis, H., Rogers, C., Taylor, Ch., Rajani, R. and Perera, D. (2019) Predicting the Physiological Effect of Revascularization in Serially Diseased Coronary Arteries: Clinical Validation of a Novel CT Coronary Angiography-Based Technique. Circulation: Cardiovascular Interventions, 12, e007577. https://doi.org/10.1161/CIRCINTERVENTIONS.118.007577

32. Lust, R., Zeri, R., Spence, P., Hopson, S., Sun, Y., Otaki, M., Jolly, S., Mehta, P. and Chitwood, W. (1994) Effect of Chronic Native Flow Competition on Internal Thoracic Artery Grafts. The Annals of Thoracic Surgery, 57, 45-50. https://doi.org/10.1016/0003-4975(94)90363-8 
33. Wahl, A., Billinger, M., Fleisch, M., Meier, B. and Seiler, Ch. (2000) Quantitatively Assessed Coronary Collateral Circulation and Restenosis Following Percutaneous Revascularization. European Heart Journal, 21, 1776-1784. https://doi.org/10.1053/euhj.2000.2129

34. Stein, P., Davis, Z., Sabbah, H. and Marzilli, M. (1979) Reduction of Coronary Flow in the Native Circulation after Bypass. Observations in a Hydraulic Model of the Cardiovascular System. The Journal of Thoracic and Cardiovascular Surgery, 78, 772-778. https://doi.org/10.1016/S0022-5223(19)38067-5

35. Guo, L., Steiman, D., Moon, B., Wan, W. and Millsap, R. (2001) Effect of Distal Graft Anastomosis Site on Retrograde Perfusion and Flow Patterns of Native Coronary Vasculature. The Annals of Thoracic Surgery, 72, 782-787. https://doi.org/10.1016/S0003-4975(01)02801-6

36. Nordgaard, H., Nordhaug, D., Kirkeby-Garstad, I., Lovstakken, L., Vitale, N. and Haaverstad, R. (2009) Different Graft Flow Patterns Due to Competitive Flow or Stenosis in the Coronary Anastomosis Assessed by Transit time Flowmetry in a Porcine Model. European Journal of Cardio-Thoracic Surgery, 36, 137-142. https://doi.org/10.1016/j.ejcts.2009.02.036

37. Rockstroh, J. and Brown, B. (2002) Coronary Collateral Size, flow Capacity and Growth: Estimates from the Angiogram in Patients with Obstructive Coronary Disease. Circulation, 105, 168-173. https://doi.org/10.1161/hc0202.102120

38. Pohl, T., Seiler, C., Billinger, M., Herren, E., Wustmann, K., Mehta, H., Windecker, S., Eberli, F. and Meier, B. (2001) Frequency Distribution of Collateral Flow and Factors Influencing Collateral Channel Development. Functional Collateral Channel Measurement in 450 Patients with Coronary Artery disease. Journal of the American College of Cardiology, 38, 1872-1878. https://doi.org/10.1016/S0735-1097(01)01675-8

39. Miyamoto, S., Fujita, M. and Sasayama, S. (2000) Bidirectional Function of Coronary Collateral Channels in Humans. International Journal of Cardiology, 75, 249-252. https://doi.org/10.1016/S0167-5273(00)00313-2

40. Berry, C., Balachandran, K., L'Allier, Ph., Lespérance, J., Bonan, R. and Oldroyd, K. (2007) Importance of Collateral Circulation in Coronary Heart Disease. European Heart Journal, 28, 278-291. https://doi.org/10.1093/eurheartj/ehl446

41. Bhatnagar, U., Nelson, G. and Stys, A. (2019) Collateral Flow Reversal: Exploring Protective Role of Collateral Circulation in Acute Coronary Syndrome. South Dakota Medicine: The Journal of the South Dakota State Medical Association, 72, 174-177.

42. Werner, G., Ferrari, M., Heinke, S., Kuethe, F., Surber, R., Richartz, B. and Figulla, H. (2003) Angiographic Assessment of Collateral Connections in Comparison with Invasively Determined Collateral Function in Chronic Coronary Occlusions. Circulation, 107, 1972-1977. https://doi.org/10.1161/01.CIR.0000061953.72662.3A

43. Wang, J., Filipovic, M., Skarvan, K., Michaux, I., Schumann, R., Buser, P. and Seeberger, M. (2006) Transesophageal Doppler Echocardiographic Detection of Intramyocardial Collateral Flow to the Right Coronary Artery and Changes in the Flow to the Inferior Left Ventricular Wall Immediately after Coronary Artery Bypass Grafting. American Journal of Cardiology, 98, 1587-1592. https://doi.org/10.1016/j.amjcard.2006.07.034

44. Zimarino, M., D'Andreamatteo, M., Waksman, R., Epstein, S. and De Caterina, R. (2014) The Dynamics of the Coronary Collateral Circulation. Nature Reviews Cardiology, 11, 191-197.

https://doi.org/10.1038/nrcardio.2013.207

45. Govindaraju, K., Badruddin, I., Viswanathan, G., Ramesh, S. and Badarudin, A. (2013) Evaluation of Functional Severity of Coronary Artery Disease and Fluid Dynamics' Influence on Hemodynamic Parameters: A Review. Physica Medica, 29, 225-232. https://doi.org/10.1016/j.ejmp.2012.03.008

46. Yamamoto, E., Saito, N., Matsuo, H., Kawase, Y., Watanabe, S., Bao, B., Watanabe, H., Higami, H., Nakatsuma, K. and Kimura. T. (2016) Prediction of the True Fractional Flow Reserve of Left Main Coronary Artery Stenosis with Concomitant Downstream Stenoses: In Vitro and in Vivo Experiments. EuroIntervention, 11, e1249-e1256. 
https://doi.org/10.4244/EIJV11I11A246

47. Uus, A., Liatsis, P., Jawaid, M., Rajani, R. and Benderskaya, E. (2015) Assessment of Stenosis Introduced Flow resistance in CCTA-Reconstructed Coronary Arteries. 2015 International Conference on Systems, Signals and Image Processing, London, 10-12 September 2015, 313-320. https://doi.org/10.1109/IWSSIP.2015.7314238

\section{NOMENCLATURE}

LMCA: left main coronary artery

LAD: left anterior descending artery

LCx: left circumflex branch

RCA: right coronary artery

$P_{\text {ao: }}$ aortic pressure

$P_{\mathrm{v}}$ : central venous pressure

$P_{\mathrm{w}}$ : pressure distal to the RCA occlusion

$Q_{\mathrm{RCAg}}$ : flow rate in the RCA graft

$Q_{\mathrm{LADg}}$ : flow rate in the LAD graft

$Q_{\mathrm{LCxg}}$ : flow rate in the LCx graft

$R_{\mathrm{LAD}}$ : resistances of the capillaries vascularized by the LAD artery

$R_{\mathrm{LCX}}$ : resistances of the capillaries vascularized by the LCx artery

$R_{\mathrm{RCAc}}$ : resistances of the capillaries vascularized by the RCA artery

$Q_{\mathrm{LADc}}$ : blood flow rate across the LAD capillaries

$Q_{\mathrm{LCX}}$ : blood flow rate across the $\mathrm{LC}_{\mathrm{X}}$ capillaries

$Q_{\mathrm{RCAc}}$ : blood flow rate across the RCA capillaries

$Q_{\text {col1 }}$ : collateral flow rate from LAD towards RCA before LAD stenoses

$Q_{\text {coll: }}$ collateral flow rate from LAD towards RCA after LAD stenoses

$Q_{\text {col2 }}$ : collateral flow rate from LCx before LCx stenoses

$Q_{\text {cols: }}$ collateral flow rate from LCx after LCx stenoses

$Q_{\text {col3 }}$ : collateral flow rate from the aorta towards the RCA

$R$ : resistance

$C$ : capacitance

$L$ : inductance

IMAG: internal mammary artery graft 